OPEN ACCESS

Edited by:

Achim Gass,

University Medical Center

Mannheim, Germany

Reviewed by:

Galit Saar,

National Institute of Neurological

Disorders and Stroke (NINDS),

United States

Yutong Liu,

University of Nebraska Medical

Center, United States

*Correspondence:

Jun Yang

imdyang@qq.com

Qinqing Li

qinqing_81@163.com

Specialty section:

This article was submitted to

Applied Neuroimaging,

a section of the journal

Frontiers in Neurology

Received: 25 September 2019

Accepted: 07 February 2020

Published: 25 February 2020

Citation:

Yang J and Li Q (2020)

Manganese-Enhanced Magnetic Resonance Imaging: Application in Central Nervous System Diseases.

Front. Neurol. 11:143.

doi: 10.3389/fneur.2020.00143

\section{Manganese-Enhanced Magnetic Resonance Imaging: Application in Central Nervous System Diseases}

\author{
Jun Yang* and Qinqing Li* \\ Department of Radiology, The Third Affiliated Hospital of Kunming Medical University, Yunnan Cancer Hospital \& Cancer \\ Center, Kunming, China
}

Manganese-enhanced magnetic resonance imaging (MEMRI) relies on the strong paramagnetism of $\mathrm{Mn}^{2+} . \mathrm{Mn}^{2+}$ is a calcium ion analog and can enter excitable cells through voltage-gated calcium channels. $\mathrm{Mn}^{2+}$ can be transported along the axons of neurons via microtubule-based fast axonal transport. Based on these properties, MEMRI is used to describe neuroanatomical structures, monitor neural activity, and evaluate axonal transport rates. The application of MEMRI in preclinical animal models of central nervous system (CNS) diseases can provide more information for the study of disease mechanisms. In this article, we provide a brief review of MEMRI use in CNS diseases ranging from neurodegenerative diseases to brain injury and spinal cord injury.

Keywords: manganese, MEMRI, central nervous system, neurodegeneration, brain injury

\section{INTRODUCTION}

Central nervous system (CNS) lesions are serious diseases affecting human health. Many imaging methods are currently available for the diagnosis and treatment of CNS diseases, and magnetic resonance imaging (MRI) is the most widely used imaging method. In addition to conventional T1-weighted imaging (T1WI) and T2-weighted imaging (T2WI), the continuous development of multiple MRI functional imaging methods [such as diffusion-weighted imaging (DWI), diffusion tensor imaging (DTI), and blood-oxygen-level dependent (BOLD) imaging] has enabled a better understanding and investigation of the occurrence, development, and prognosis of CNS diseases. Manganese enhanced magnetic resonance imaging (MEMRI) is a special MR functional imaging method, which is different from other imaging methods. For example, DWI has a limited ability to detect complex fiber connections and has low sensitivity in tracking subcortical fibers, leading to underestimation of nerve fiber connections, whereas MEMRI can produce results comparable to histological results (1). DTI can be used to evaluate neural connectivity and the integrity of nerve fiber tract, but cannot assess the dynamics of axonal transport, whereas MEMRI can measure axonal transport functions (2-4). BOLD imaging provides a hemodynamic-dependent measurement of the spatial location and extent of neuronal activity but with poor specificity, whereas MEMRI directly measures neuronal activity in brain areas by assessing dynamic changes in calcium signals (5). PET and SPECT only measure brain activity through an assessment of metabolic changes, but the spatial resolution is low; thus, the ability of this technique to distinguish brain microstructures is limited.

$\mathrm{Mn}^{2+}$ has strong paramagnetism, significantly reduces the T1 relaxation time, and exhibits a high signal on T1WI, which is the basis of MEMRI. $\mathrm{Mn}^{2+}$ is a $\mathrm{Ca}^{2+}$ analog that is absorbed by excitable cells through voltage-gated calcium channels [particularly L-type $\mathrm{Ca}_{\mathrm{v}} 1.2$ channels (6)], $\mathrm{Na}^{+}-\mathrm{Ca}^{2+}$ exchangers on the cell membrane (7-10) in addition to other routes of $\mathrm{Na}^{+} / \mathrm{Mg}^{2+}$ antiporters, transferrin and divalent metal transporter-1 (DMT1) (11-13). At present, MEMRI is 
mainly used in three areas: studies of anatomy and cellular structure (14-18), tracing of neural connections (5, 19, 20), and brain function (21-26). After entering into cells, $\mathrm{Mn}^{2+}$ is transported along neurons via microtubule-dependent axonal transport and reaches secondary neurons by transport across synapses, thereby enabling anterograde tracing of associated neural pathways (27-29). For the study of brain function, activity-induced manganese-dependent MRI (AIM-MRI) is a kind of MEMRI method used to detect preferentially active neural regions during a task such as light, odor, pain, sensory, drug or behavioral stimulation $(30,31)$. This method is directly dependent on the activity of neurons and is independent of hemodynamics (32). Many types of CNS diseases exist, and animal experiments are required to investigate such diseases in most cases. Due to the unique advantages of MEMRI, its applications are gradually increasing in studies relevant to CNS diseases. This review focuses on animal models of CNS diseases.

\section{$M^{2+}$ ADMINISTRATION METHOD}

The routes of $\mathrm{Mn}^{2+}$ administration in MEMRI are mainly local administration (LA) and systemic administration (SA). SA is performed through oral gavage or intravenous, intraperitoneal, subcutaneous, or intramuscular injection and enables observation of the scopes and boundaries of anatomical structures (33). Intracerebral administration has been used to inject $\mathrm{Mn}^{2+}$ into different regions of the brain to study connectivity and axonal transport. A summary of MEMRI studies using local $\mathrm{Mn}^{2+}$ administration is provided in Table $\mathbf{1}$. Other methods of administration include nasal lavage and intravitreal, intrathecal, subdural, inner ear, subarachnoid, and intraventricular injection $(60,61,65,71,74-76)$.

SA is mainly used in preclinical experimental studies. Most $\mathrm{Mn}^{2+}$ reaches the brain parenchyma through the bloodbrain barrier (BBB) and blood-cerebrospinal fluid barrier [(77, 78); Figure 1A], thus enhancing visualization of neuronal structures and highlighting functionally active brain regions. An intravenous injection of mangafodipir (a manganese-based chelate contrast agent) in healthy volunteers provided good visualization of the choroid plexus, anterior pituitary, and exocrine glands in the head and neck (79). Oral administration is mainly used to study the hepatobiliary system and is rarely used to examine the CNS. Qiu et al. (80) studied differences in cerebral development between male and female mice, and MEMRI was performed in neonatal mice after they ingested $\mathrm{Mn}^{2+}$ in milk produced by the lactating mother. A major challenge with SA is the adverse effects of $\mathrm{Mn}^{2+}$, which will be discussed in the toxicity section.

Nasal administration is an effective LA method for examination of the CNS using MEMRI (Figure 2). Nasal administration avoids the adverse effects of SA. In the study by Fa et al. (23), the visual cortex of rats was observed using AIMMRI after perfusion of $\mathrm{MnCl}_{2}$ in the nasal cavity, and $\mathrm{Mn}^{2+}$ migrated from the olfactory bulb to the visual cortex. When the rats were presented with different odors after intranasal instillation of $\mathrm{MnCl}_{2}$, differences in the signal intensity of $\mathrm{Mn}^{2+}$ were observed in the primary olfactory cortex of rats depending on these odors (25). The signal intensity of MEMRI generally increases as the $\mathrm{MnCl}_{2}$ concentration increases, but the signal intensity can be saturated. Moreover, the application of $\mathrm{MnCl}_{2}$ solutions with excessively high concentrations in the nasal cavity will also cause olfactory damage (81), which is occasionally accompanied by inflammatory reactions (82).

$\mathrm{Mn}^{2+}$ administration via the visual pathway is also an LA route and mainly includes intraocular injection and a local drip. Intraocular injections are more frequently used, and MRI after an intravitreal injection of $\mathrm{MnCl}_{2}$ allows researchers to observe the entire visual pathway from the retina, optic nerve, optic chiasm, lateral geniculate nucleus, and superior colliculus to the visual cortex (Figures 1B-D). Administration of lowdose $\mathrm{MnCl}_{2}$ produces good enhancement on MEMRI without significant damage to the ocular structure, but administration of $\mathrm{Mn}^{2+}$ doses $>1,500 \mathrm{nmol}$ decreased the number of retinal ganglion cells (RGCs) (83). Local drip is a noninvasive method and is currently being used in experimental research. After a local drip of a $\mathrm{MnCl}_{2}$ solution, $\mathrm{Mn}^{2+}$ is rapidly distributed to the aqueous humor, while the concentration of $\mathrm{Mn}^{2+}$ in the vitreous body exhibits fewer fluctuations throughout the process (84). According to Sun et al. (85), locally dripped $\mathrm{MnCl}_{2}$ solutions $(1$ and $1.5 \mathrm{M}$ ) did not diffuse into the vitreous cavity, possibly reached the retina through the capillary circulation after iris absorption, and were then transported to the superior colliculus. This method is safe and does not damage the visual system. The authors further showed that an acidic $\mathrm{MnCl}_{2}$ solution produced more pronounced MEMRI signal intensity than a neutral solution, and the use of longer intervals between repeated local $\mathrm{Mn}^{2+}$ doses can reduce adverse effects (86). In addition, $\mathrm{MnCl}_{2}$ can be injected through the anterior chamber for imaging $(87,88)$ and subsequently reveals the structure of the visual system. However, this method is used less frequently because it is more invasive than local drip administration and does not result in direct retinal uptake of $\mathrm{Mn}^{2+}$ in contrast to intravitreal injection.

\section{TOXICITY}

Manganese is one of the basic trace elements needed for development, but excess manganese intake can cause poisoning. Excess manganese often accumulates in organs such as the liver, pancreas, bones, kidneys, and brain, causing liver damage, neurotoxicity, impaired cardiovascular function, and even death (89). In the chronic stage, excessive manganese accumulation in the brain striatum can lead to Parkinson's disease-like symptoms (29). Currently, the main reason why manganese-containing contrast agents have not been widely used in clinical practice is the neurotoxic effect of $\mathrm{Mn}^{2+}$. Researchers administer $\mathrm{Mn}$ contrast agents through either systemic routes or local routes to study the CNS. SA is simple and noninvasive and can be repeated as needed. However, one major disadvantage is that the dose of $\mathrm{MnCl}_{2}$ is significantly higher than the dose used for LA, and $\mathrm{Mn}^{2+}$ reaches the liver, heart, and kidney before reaching the brain, increasing the risk of acute toxicity (90). 
TABLE 1 | Summary of MEMRI studies using local administration of $\mathrm{Mn}^{2+}$.

\begin{tabular}{|c|c|c|c|c|c|}
\hline Animal strains & Injection site & Dose & MRI & Interest & References \\
\hline C57BL/6J mice & Hippocampus & $0.25 \mu \mathrm{l}, 5-200 \mathrm{mM}$ & $2.35 \mathrm{~T}$ & Neural pathways & $(14,34)$ \\
\hline Lewis rats & Visual cortex & $60 \mu \mathrm{g} / \mathrm{kg}, 60 \mathrm{mg} / \mathrm{kg}$ & $4.7 \mathrm{~T}$ & Visual cortex; corpus callosum & (35) \\
\hline Wistar rats & Entorhinal cortex & $40 \mathrm{nl}, 1 \mathrm{M}$ & $4.7 \mathrm{~T}$ & Hippocampus & $(36)$ \\
\hline SD rats & Entorhinal cortex & $100 \mathrm{nl}, 100 \mathrm{mM}$ & $4.7 \mathrm{~T}$ & Hippocampo-thalamic network & $(37)$ \\
\hline SD rats & Raphe interpositus nucleus & $0.4 \mu \mathrm{l}, 0.08 \mathrm{M}$ & $4.7 \mathrm{~T}$ & Lateral habenula & (38) \\
\hline Mice & Hippocampus & $3-5 \mathrm{nl}, 200 \mathrm{mM}$ & $11.7 \mathrm{~T}$ & $\begin{array}{l}\text { Hippocampal to basal forebrain } \\
\text { transport }\end{array}$ & (39) \\
\hline Marmoset & $\begin{array}{l}\text { Forelimb primary motor } \\
\text { cortex }\end{array}$ & $\begin{array}{l}0.16 \mu \mathrm{l}, 800,400,40 \text {, and } 8 \\
\mathrm{nmol}\end{array}$ & 3.0 T & Corticospinal tract & $(40)$ \\
\hline Mice & Prefrontal cortex & $5 \mathrm{nl}, 600 \mathrm{mM}$ & $11.7 \mathrm{~T}$ & Neurocircuitry & $(41,42)$ \\
\hline SD rats & Ventral tegmental area & $100 \mathrm{nl}, 200 \mathrm{mM}$ & $4.7 \mathrm{~T}$ & $\begin{array}{l}\text { Neuronal projections from ventral } \\
\text { tegmental area to forebrain }\end{array}$ & $(43)$ \\
\hline Monkey & $\begin{array}{l}\text { Orbitofrontal/ anterior } \\
\text { cingulate cortex }\end{array}$ & $\begin{array}{l}0.2 \sim 0.5 \mu \mathrm{l}, 800 \text { or } \\
120 \mathrm{mM}\end{array}$ & $4.7 \mathrm{~T}$ & Prefrontal circuits & $(44)$ \\
\hline Wistar rats & Sensorimotor cortex & $0.2 \mu \mathrm{l}, 1 \mathrm{M}$ & $4.7 \mathrm{~T}$ & Neuronal connectivity & $(45,46)$ \\
\hline SD rats & Sensorimotor cortex & $0.2 \mu \mathrm{l}, 1 \mathrm{M}$ & $3.0 \mathrm{~T}$ & Neuronal connective pathways & $(47)$ \\
\hline SD rats & Intracortical/ Motor cortex & $0.2 \mu \mathrm{l}, 1 \mathrm{M}$ & $9.4 \mathrm{~T}$ & Spinal cord/ Corticospinal tract & $(48,49)$ \\
\hline C57/BL6 mice & Striatum/ Amygdala & $10 \mathrm{nl}, 5 \mathrm{mM}$ & $11.7 \mathrm{~T}$ & $\begin{array}{l}\text { Tract tracing from striatum and } \\
\text { amygdala }\end{array}$ & (19) \\
\hline Mice & Hippocampus & $5 \mathrm{nl}, 500 \mathrm{mM}$ & $11.7 \mathrm{~T}$ & Hippocampal circuitry & $(50)$ \\
\hline C57BL6 & $\begin{array}{l}\text { Primary somatosensory } \\
\text { cortex }\end{array}$ & $60 \mathrm{nl}, 100 \mathrm{mM}$ & $7.0 \mathrm{~T}$ & Somatosensory cortex & $(51)$ \\
\hline SD rats & $\begin{array}{l}\text { Lateral geniculate nucleus/ } \\
\text { visual cortex }\end{array}$ & $\begin{array}{l}30 \mathrm{nl}, 100 \mathrm{mM} ; 100 \mathrm{nl} \\
100 \mathrm{mM}\end{array}$ & $7.0 \mathrm{~T}$ & $\begin{array}{l}\text { Lateral geniculate nucleus; visual } \\
\text { cortex }\end{array}$ & $(20)$ \\
\hline SD rats & Somatosensory cortex & $200 \mathrm{nl}, 60 \mathrm{mM}$ & $11.7 \mathrm{~T}$ & $\begin{array}{l}\text { Corticocortical and thalamocortical } \\
\text { connectivity }\end{array}$ & $(52)$ \\
\hline SD rats & Habenular nucleus & $0.005 \mu l, 4 \mathrm{M}$ & $7.0 \mathrm{~T}$ & Habenular nucleus tract & $(53)$ \\
\hline SD rats & Raphe nucleus & $0.15 \mu \mathrm{l}, 0.1 \mathrm{M}$ & $7.0 \mathrm{~T}$ & Dorsal raphe forebrain tract & $(54)$ \\
\hline SD rats & Thalamus & $200 \mathrm{nl}, 10 \sim 60 \mathrm{mM}$ & $11.7 \mathrm{~T}$ & Cortical laminar architecture & $(15)$ \\
\hline SD rats & Orbitofrontal cortex & $200 \mathrm{nl}, 80 \mathrm{mM}$ & $4.7 \mathrm{~T}$ & Orbitofrontal neuronal activity & $(55)$ \\
\hline SD rats & Somatosensory cortex & $\sim 10 \mathrm{nl}, 0.8 \mathrm{M}$ & 3.0 T & Major brain projection systems & $(56)$ \\
\hline Rhesus macaques & Frontal eye fields & $0.3 \mu \mathrm{l}, 120 \mathrm{mM}$ or $300 \mathrm{mM}$ & $7.0 \mathrm{~T}$ & Frontal eye fields connections & $(1)$ \\
\hline SD rats & Spinal cord & $10 \mathrm{nl}, 25 \mathrm{mmol} / \mathrm{l}$ & $9.4 \mathrm{~T}$ & Spinal cord & $(57)$ \\
\hline SD rats & Spinal cord & 30 or 60 nl, 100 or 800 mM & $7.0 \mathrm{~T}$ & Spinal cord & $(58)$ \\
\hline Wistar rats & Spinal cord & $50 \mathrm{nl}, 10 \mathrm{mM}$ & $4.7 \mathrm{~T}$ & Spinal cord & (59) \\
\hline SD rats & Cisterna magna & $50 \mu \mathrm{l}, 25 \mathrm{mM} ; 25 \mu \mathrm{l}, 50 \mathrm{mM}$ & $4.7 \mathrm{~T}$ & Brain & $(60)$ \\
\hline SD rats & Subarachnoid space & $50 \mu \mathrm{l}, 10 \mathrm{mM}$ & $4.7 \mathrm{~T}$ & Spinal cord & $(61)$ \\
\hline SD rats & Cisterna magna & $80 \mu \mathrm{l}, 0.8 \mathrm{mM}$ & $1.5 \mathrm{~T}$ & Spinal cord & $(62)$ \\
\hline SD rats & Cisterna magna & $80 \mu \mathrm{l}, 0.8 \mathrm{M}$ & $1.5 \mathrm{~T}$ & Spinal cord & $(63)$ \\
\hline Mice & $\begin{array}{l}\text { Cisterna magna, Lateral } \\
\text { ventricles }\end{array}$ & $0.5 \mu \mathrm{l}, 0.8 \mathrm{M} ; 0.25 \mu \mathrm{l}, 0.8 \mathrm{M}$ & $1.5 \mathrm{~T}$ & Spinal cord & (64) \\
\hline C57/BL6 mice & Lateral ventricle & $0.25 \mu \mathrm{l}, 5 \mathrm{mM}$ & $2.35 \mathrm{~T}$ & Neural pathways & $(14)$ \\
\hline SD rats & Lateral ventricles & $2 \mu \mathrm{l}, 0.2 \mathrm{~mol} / \mathrm{l}$ & 3.0T; 7.0 T & Brain and spinal cord; spinal injury & $(65,66)$ \\
\hline SD rats, Wistar rats & Lateral ventricle & $6 \mu \mathrm{l}, 0.17 \mathrm{M}$ & $4.7 \mathrm{~T}$ & Spinal cord & $(67-69)$ \\
\hline Wistar rats & Lateral ventricle & $10 \mu \mathrm{l}, 50 \mathrm{mM}$ & $4.7 \mathrm{~T}$ & Hippocampal & $(70)$ \\
\hline Wistar rats & Below the dura & $200 \mathrm{nl}, 0.3 \mathrm{M}$ & $7.0 \mathrm{~T}$ & Corticothalamic pathway & $(71)$ \\
\hline SD rats & Transcranial & $500 \mathrm{mM}$ or $250 \mathrm{mM}$ & $11.7 \mathrm{~T}$ & Traumatic brain injury & $(72)$ \\
\hline SD rats & Transcranial & $\sim 50 \mu \mathrm{I}, 100,250,500 \mathrm{mM}$ & $11.7 \mathrm{~T}$ & Neuronal tract tracing & (73) \\
\hline
\end{tabular}

The use of fractional or continuous infusions of low doses for SA has been shown to reduce the toxic effects of $\mathrm{MnCl}_{2}$. Some studies have used low-dose, fractional administration methods to achieve good imaging effects while avoiding the toxic side effects of $\mathrm{MnCl}_{2}(26,91,92)$. Using subcutaneous or intraperitoneal implantation of micro-osmotic pumps to continuously administer low doses of $\mathrm{MnCl}_{2}$ can produce a better enhancement effect than bolus or fractional administration 

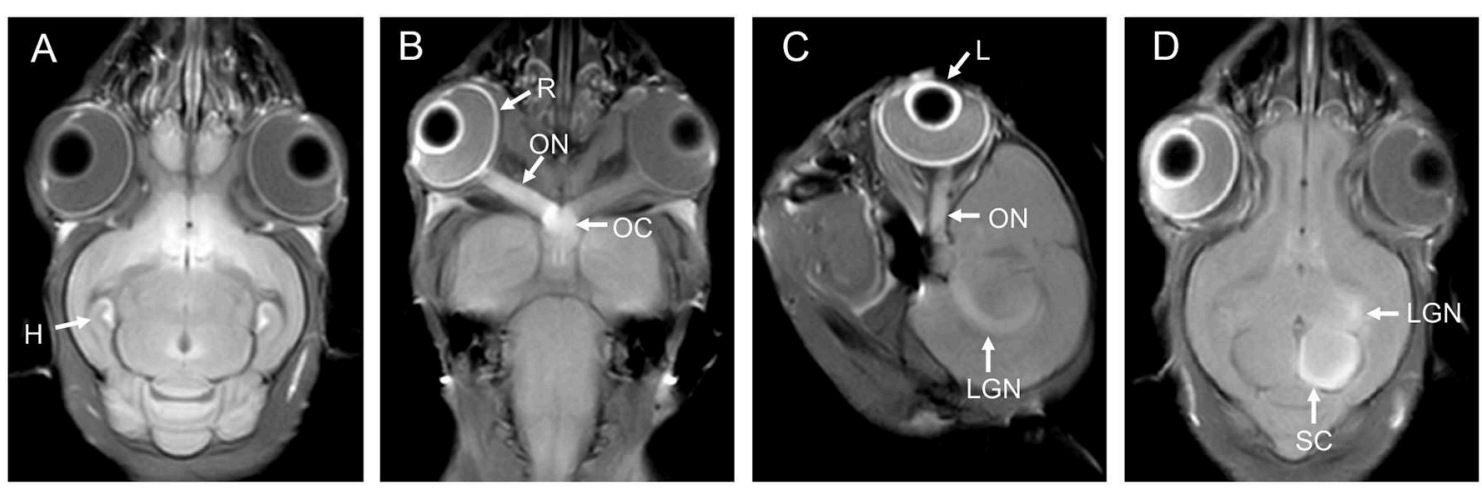

FIGURE 1 | (A) is the brain of a tree shrew in MEMRI after $\mathrm{MnCl}_{2}$ intraperitoneal administration $24 \mathrm{~h}$. The hippocampus can be observed enhancement. (B-D) are the visual pathways of a tree shrew in MEMRI. MEMRI can be used to observe visual pathways from the retina, optic nerve, optic chiasm, lateral geniculate nucleus, and superior colliculus after intravitreal injection of $\mathrm{MnCl}_{2}$ in a tree shrew (a kind of squirrel-like mammal which is the closest to primates). $\mathrm{H}$, hippocampus; $\mathrm{R}$, retina; $\mathrm{L}$, lens; ON, optic nerve; OC, optic chiasm; LGN, lateral geniculate nucleus; SC, superior colliculus.

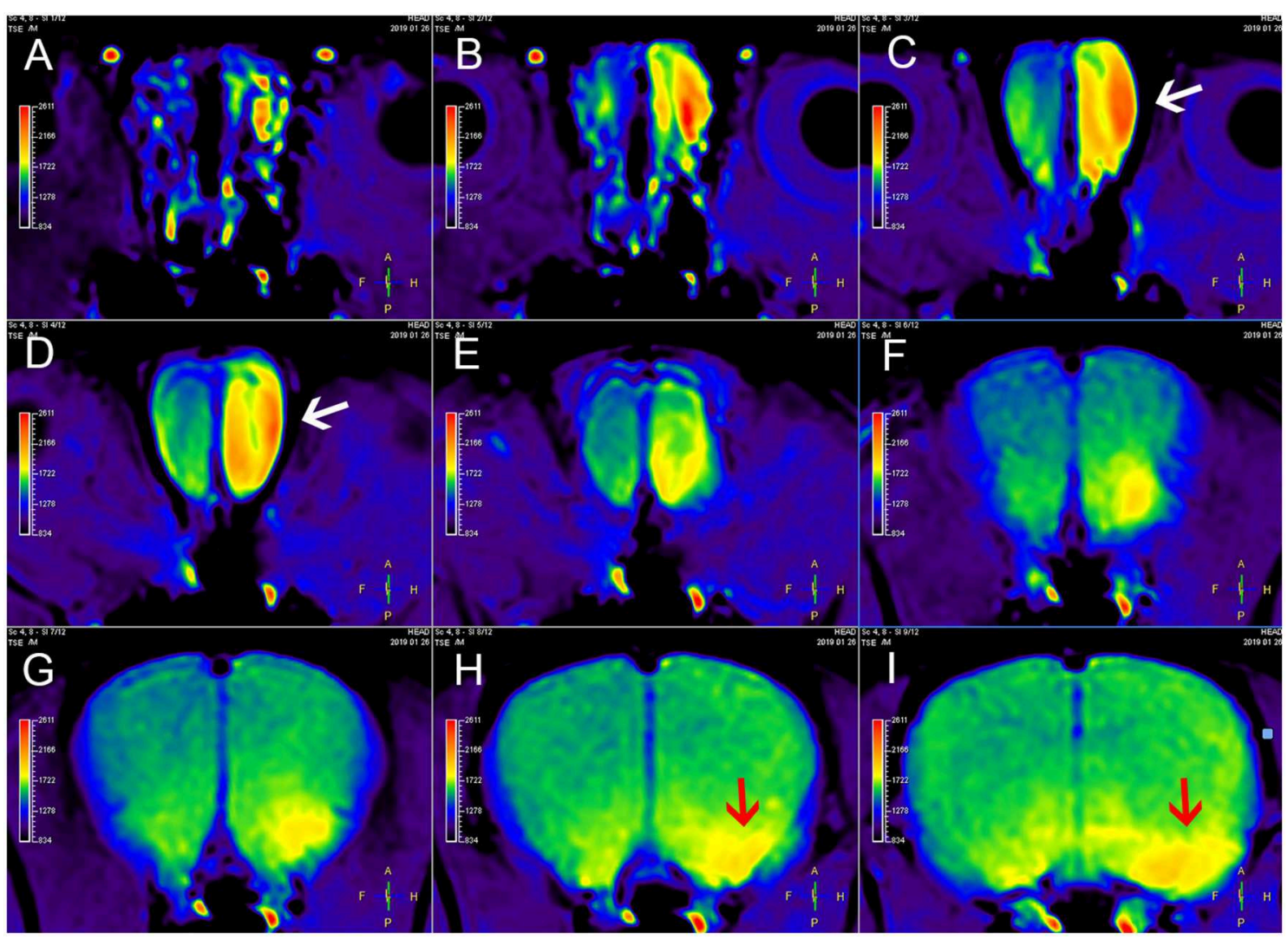

FIGURE 2 | MEMRI of a rat using left nasal administration of $\mathrm{MnCl}_{2}$. $\mathrm{Mn}^{2+}$ uptake into the olfactory bulb (white arrows) and transport to olfactory cortex along the olfactory pathway. The red arrows indicate the lateral olfactory tract with unilateral enhancement. From (A-I) are axial continuous images of rat brain MRI.

(93-95). Local injections reduce the systemic toxic side effects of manganese but cause certain trauma during the administration process, and the technical requirements for administration are high. For example, precise stereotaxic positioning is required to reach the target area when injecting manganese into a specific brain region. Different studies have used different doses and routes of administration, but the lowest doses that achieve the desired MRI signals should be used to reduce the systemic and local toxic side effects of $\mathrm{Mn}^{2+}$. The signal intensity of MEMRI is related to the concentration of $\mathrm{Mn}^{2+}$, but excessive $\mathrm{Mn}^{2+}$ levels can damage different tissues. Thus, the concentration must be balanced according to the actual experimental situation. 


\section{NEURODEGENERATIVE DISEASES}

\section{Alzheimer's Disease (AD)}

$\mathrm{AD}$ is a neurodegenerative disease and the most common cause of dementia. Neuropathological features of AD include neurofibrillary tangles (NFTs) and the formation of neuritic amyloid- $\beta(\mathrm{A} \beta)$ plaques. The brains of patients with $\mathrm{AD}$ contain a large amount of hyperphosphorylated tau protein. Under these conditions, the normal functions of the tau protein are either inhibited or lost, and paired helical filaments or NFTs associated with synaptic damage begin to appear (96). MEMRI can detect neuronal dysfunction at an early stage and contributes to early detection of the disease. Fontaine et al. used a quantitative $\Delta R 1$ value $\left(\Delta R 1=R 1_{6 h}-R 1_{\text {baseline }}\right)$ and intraperitoneal $\mathrm{MnCl}_{2}$ injection to detect markedly abnormal elevations in $\triangle \mathrm{R} 1$ in the hippocampal $\mathrm{CA} 1$ and $\mathrm{CA} 3$ regions before the onset of cognitive deficits in tau protein transgenic mice (rTg4510) (97). In another AD model (5XFAD mice), MEMRI with SA of $\mathrm{Mn}^{2+}$ showed increased signal intensity in brain areas associated with spatial cognition in the early stages of the disease (2-5 months of age); this increased intensity was associated with impaired learning and memory in behavioral tests (98). The increase in the degree of MEMRI enhancement may be related to abnormal changes in brain waves, and changes in electroencephalograms occur earlier than abnormal changes in memory (99). Moreover, $\mathrm{MnCl}_{2}$ absorption may be increased due to inflammatory responses as $\mathrm{Mn}^{2+}$ enhancement is increased in the presence of increasing inflammation in a stroke model (100). MEMRI also detects depolarization due to reduced calcium influx after oxidative stress-mediated damage to the L-type calcium channel in the hippocampus (CA1d region) of 5xFAD mice via SA of $\mathrm{Mn}^{2+}$ (101). Notably, in another study using an APPxPS1 knock-in AD mouse model, MEMRI did not recognize abnormal neuronal activity in various brain regions probably due to increased $\mathrm{Mn}^{2+}$ diffusion associated with increased $\mathrm{BBB}$ permeability in the $\mathrm{AD}$ model and the lack of correlation between $\mathrm{Mn}^{2+}$ deposition and local neuronal activity (102).

Rhinencephalon-based MEMRI is widely used to study $\mathrm{AD}$ and is mainly used to detect structural changes in the olfactory bulb and the axonal transport function and to evaluate therapeutic effects after treatment. Smith et al. (103) used nasal $\mathrm{Mn}^{2+}$ administration for MEMRI to quantitatively evaluate the axonal transport function in animals with tau protein lesions. In this study, the axonal transport rate in $\mathrm{Tg} 2576$ mice (an $\mathrm{AD}$ animal model) was normal before $\mathrm{A} \beta$ deposition, decreased significantly as the $A \beta$ level increased before plaque formation, and substantially decreased after plaque formation. $\mathrm{A} \beta$ deposition in the olfactory bulb occurs earlier than in other brain region and is responsible for the decrease in olfactory function observed in subjects with early AD (104). Overexpression of amyloid precursor protein (APP) is also a hallmark of $\mathrm{AD}$, leading to elevated levels of $\mathrm{A} \beta 42$ and the formation of neuritic plaques that result in oxidative stress, inflammatory responses, and subsequent neuronal damage (105). Saar et al. (106) used an AD mouse model overexpressing APP and observed changes in the signal intensity in the olfactory bulb following SA via tail vein injection. Since overexpressed APP damages the layered structure of the olfactory bulb, the glomerular layer of the olfactory bulb presents reduced $\mathrm{Mn}^{2+}$ enhancement and volume. The $\mathrm{Mn}^{2+}$ enhancement of the glomerular layer is increased 1 week after doxycyclineinhibited APP overexpression and gradually returns to normal after 3 weeks. Based on this finding, changes in MEMRI signal intensity in the layers of the olfactory bulb can be used to monitor neurodegenerative changes. In some studies, intranasal perfusion of $\mathrm{MnCl}_{2}$ was used for imaging. MEMRI detected a decrease in the axonal transport rate of the rhinencephalon before the formation of $\mathrm{A} \beta$ plaques. The axonal transport rate showed a continuous decrease with the formation of $A \beta$ plaques, and the transport function was gradually restored after treatment (107). In a similar study, MEMRI with nasal administration of $\mathrm{Mn}^{2+}$ in $\mathrm{rTg} 4510$ transgenic mice revealed an age-dependent axonal transport defect in the rhinencephalon, which was observed beginning at 3 months and until the formation of pathological tau proteins (108). Other similar studies using AD animal models (APP-knockout mice, 3xTg$\mathrm{AD}$ mice, and JNPL3 tauopathy mice) have revealed axonal transport disorders in the brain prior to the formation of $A \beta$ plaques $(2,109)$, and the axonal transport of $\mathrm{Mn}^{2+}$ decreases with the pathological increase in the levels of the tau protein (110). Treatment of Tg2576 mice with R-flurbiprofen (a selective A $\beta 42$-reducing agent) before the formation of $A \beta$ plaques increased the axonal transport of $\mathrm{Mn}^{2+}$, and mice that were treated after plaques formed also showed an improved axonal transport capacity. However, the mechanisms are different, and the latter treatment strategy mainly relies on reducing tau hyperphosphorylation (111).

In addition to $\mathrm{SA}$ and nasal administration, $\mathrm{Mn}^{2+}$ can be directly injected into specific brain regions to trace neuronal connections in the brain and has been used to detect impairments in the intracellular transport function. In an APP-knockout mouse model, $\mathrm{Mn}^{2+}$ transport from the hippocampus to the septal nucleus and amygdala was reduced $7 \mathrm{~h}$ after $\mathrm{MnCl}_{2}$ injection into the CA3 region, and $\mathrm{Mn}^{2+}$ transport to the contralateral hippocampus was reduced after $25 \mathrm{~h}$ (50), suggesting that the transport function was impaired. A similar study analyzed the transport function in mice at different ages by injecting $\mathrm{Mn}^{2+}$ into the CA3 region of APP SwInd transgenic mice and wild-type mice. $\mathrm{Mn}^{2+}$ transport along the hippocampus to the basal forebrain pathway was decreased with aging, and the decrease was more pronounced in aged APP SwInd transgenic mice. Thus, with aging, the natural degeneration of neurons is further aggravated by APP overexpression and $A \beta$ plaque formation (112). Medina et al. studied the mechanism underlying the decrease in axonal transport and found that knockout of microtubule motor kinesin light chain-1 (KLC-1) decreases $\mathrm{Mn}^{2+}$ transport from the hippocampus to the forebrain, but this effect is weak (39), and other kinesins or motor molecules may also play a role in axonal transport. 


\section{Parkinson's Disease (PD)}

$\mathrm{PD}$ is a slowly progressive, neurodegenerative dyskinesia with clinical manifestations of bradykinesia and additional motor symptoms including muscle stiffness, static tremor, and progressive posture and gait instability (113). The most important pathological feature of PD is the degeneration and death of dopaminergic neurons in the substantia nigra pars compacta $(\mathrm{SNc})$ of the midbrain, resulting in a significant reduction in the striatal dopamine content and subsequent disease onset.

An animal model of PD was established using MPTP (1-methyl-4-phenyl-1,2,4,5-tetrahydropyridine) to induce dopaminergic (DAergic) neuron death in the SNc (114). In rats with MPTP-induced PD, MPTP injury resulted in a decrease in neuronal activity and density in the nigrostriatal DAergic system and CA1, CA3, and dentate gyrus (DG) regions of the hippocampus, as well as a decrease in neurogenesis in the DG, but an increase in the activity of the subthalamic nucleus (STN). The hippocampal R1 value on MEMRI following systemic injection of $\mathrm{MnCl}_{2}$ was positively correlated with the neuron density, and the R1 value of the STN was positively correlated with neuronal activity but negatively correlated with the density of DAergic neurons in the SNc. The R1 value on MEMRI was proposed as an indicator of PD severity and treatment outcomes (115). In mice with MPTP-induced PD (intraperitoneal administration of $\mathrm{Mn}^{2+}$ ), an increase in $\mathrm{Mn}^{2+}$ uptake during the first few days was postulated to be caused by increased astrocyte reactivity due to early striatum terminal degeneration, whereas the enhancement of the MEMRI signal was reduced after anti-inflammatory treatment using vasoactive intestinal peptide receptor 2 agonists, thus facilitating neuronal protection (116). Quantitative AIMMRI uses a quantitative $\mathrm{T} 1$ value (or $\mathrm{R} 1$ value $=\mathrm{T} 1^{-1}$ ) to quantify the neuronal activity map of the entire brain, revealing the patterns and locations of changes in neuronal activity in animal models of PD. In particular, a quantitative analysis of the $\mathrm{R} 1$ value in the dorsal caudate-putamen determines the severity of PD and thus facilitates proper treatment (117). Unilateral SNc injury in the rat model of 6-hydroxydopamine (OHDA)-induced $\mathrm{PD}$ causes bilateral changes, and the T2 relaxation time of the bilateral SNc increases on MRI. Meanwhile, DTI reveals changes in the axial and radial diffusivities of 6-OHDA in the SNc reticulata and cortex at three and 14 days after 6-OHDA injection, indicating changes in the microstructures of these regions. In addition, MEMRI (local injection of $\mathrm{Mn}^{2+}$ into the STN) shows a decrease in the axonal transport function from the ipsilateral STN to the ventral globus pallidus (118). Some researchers have used MEMRI to study neural connections in $\mathrm{PD}$ models. In the rat model of 6-OHDA-induced PD, $\mathrm{Mn}^{2+}$ infusion into the $\mathrm{SNc}$ revealed an enhanced signal in the anterior thalamus and habenular nucleus, and an injection of $\mathrm{Mn}^{2+}$ into the habenular nucleus revealed an enhanced signal in the interpeduncular nucleus and raphe, suggesting increased connectivity between the hemispheres of the basal ganglia (119) and reduced connectivity between the raphe and the lateral habenular nucleus, DG, thalamus, and hypothalamus. Apomorphine treatment (a dopamine replacement therapy) partially restores the raphe connections and reduces depressive symptoms (38). Based on these studies, MEMRI not only detects neurodegeneration and dysfunction but also serves as an imaging method to monitor the efficacy of drug treatment.

\section{Amyotrophic Lateral Sclerosis (ALS)}

ALS is a neurodegenerative disease that affects human motor neurons and other neuronal cells, leading to severe disability, and some critically ill patients eventually die of respiratory failure. The diagnosis of ALS is based on a painless and progressive functional decline and upper and lower motor neuron dysfunction (120). Mutations in some genes [tubulin alpha 4A (TUBA4A), profilin 1 (PFN1), dynactin 1 (DCTN1), and neurofilament heavy subunit $(\mathrm{NEFH})]$ that are expressed during the progression of pathogenesis may cause axonal transport dysfunction (121). Additional studies have used conventional MRI, such as T2 mapping, DWI, and DTI, to study axonal changes in animal models, whereas studies using MEMRI are relatively rare. In the ALS model of SOD1-G93A mice, MEMRI (nasal administration of $\mathrm{MnCl}_{2}$ ) was used to estimate the axonal transport rate, and anterograde axonal transport was significantly reduced in the rhinencephalon of ALS mice but returned to normal after acute treatment with davunetide (a neuroprotective compound that facilitates microtubule stabilization and repair). In addition, tau hyperphosphorylation associated with microtubule dysfunction and impaired axonal transport was observed in ALS mice, and chronic treatment with davunetide significantly reduced tau hyperphosphorylation (122). By achieving a better understanding of axonal transport dysfunction in ALS patients, MEMRI will be increasingly used in future studies to assess the axonal transport function and for post-treatment evaluations.

\section{Multiple Sclerosis (MS)}

MS is an autoimmune disease in the CNS characterized by demyelination and simultaneous axonal and neuronal degeneration. Optic neuritis is one of the most common manifestations of MS and can gradually lead to vision loss. MEMRI has been used in animal models of optic neuritis and MS and can be used to assess the axonal transport function of the optic nerve $(3,123)$. Experimental autoimmune encephalomyelitis (EAE) is a chronic inflammation model and a major animal model of MS (124). As shown in the study by Boretius et al. using a rat EAE model, the high signal intensity on T2WI and enhancement mediated by the conventional MRI contrast agent Gd-DTPA are highly sensitive to optic nerve damage. However, the technique was unable to distinguish between mild, moderate, and severe lesions, while MEMRI signal enhancement was positively correlated with the severity of axonal loss, and $\mathrm{Mn}^{2+}$ tended to accumulate in the central part of the inflamed optic nerve possibly due to intracellular $\mathrm{Ca}^{2+}$ overload (123). In the group with moderate and severe optic neuritis, the rate of $\mathrm{Mn}^{2+}$ accumulation and the axonal transport rate (intravitreal injection of $\mathrm{MnCl}_{2}$ ) were significantly lower than those in the control group, and the change in axonal transport was associated with visual function and structural damage (3). The mechanism by which this inflammation causes axonal degeneration may be direct damage caused by $\mathrm{Ca}^{2+}$ influx to the 
axon from $\mathrm{N}$-type voltage-dependent calcium channels and/or activated macrophages/microglia, thereby promoting secondary axonal injury (125). Treatment with calpain inhibitors not only reduces calpain activity but also protects RGCs from preclinical degeneration (126).

In clinical practice, corpus callosum atrophy is observed in patients with MS. Another study used an EAE mouse model to study changes in corpus callosum connections. $\mathrm{Mn}^{2+}$ was directly injected into the visual cortex, and MEMRI was used to track changes in the corpus callosum over time. At $7 \mathrm{~h}$ after $\mathrm{Mn}^{2+}$ injection, the signal intensity along the corpus callosum and contralateral visual cortex was higher in the EAE group than that in the control group. At $12-14 \mathrm{~h}$ after $\mathrm{Mn}^{2+}$ injection, the signal enhancement of the EAE group was significantly higher than that of the control group. This difference may be due to the significant increase in the intracellular $\mathrm{Ca}^{2+}$ concentration, thus resulting in an ion imbalance (35).

\section{Glaucoma}

Glaucoma is one of the main causes of irreversible blindness. Because the disease can progress for many years before symptoms occur, it is called the "sneaky thief of sight" (127). Glaucoma is characterized by progressive degeneration of RGCs. MEMRI was conducted $2-5 \mathrm{~h}$ after intravitreal injection of $\mathrm{Mn}^{2+}$ at 2 and 6 weeks after establishment of a rat glaucoma model. MEMRI revealed a delayed increase in signal intensity at 6 weeks. In addition, $\mathrm{Mn}^{2+}$ accumulated in the vitreous body, and the concentration was particularly high in the optic disc and retina. The higher signal intensity observed in the vitreous humor may be due to blockage of the trabecular pathway for scleral and limbal vein drainage due to photocoagulation during model establishment (128), the combined effects of RGC apoptosis, a decreased number and density of optic nerve axons, or blockade of axonal transport in the head of the ganglion despite the presence of living cells (129). In a hereditary glaucoma model using DBA/2J mice (whose optic nerve axonal degeneration and intraocular pressure depend on age), the periocular circumference is related to the total retinal thickness, retinal inner layer thickness, ciliary body area, optic disc width, and angulus iridocornealis. Retinal $\mathrm{Mn}^{2+}$ uptake decreases with age in old DBA/2J mice, and loss of axonal transport occurs before changes in retinal thickness (130). The visual pathway showed a significant reduction in $\mathrm{Mn}^{2+}$ enhancement at 9 months and little enhancement by 12 months in DBA/2J mice (131), and early axonal transport may be impaired before elevated intraocular pressure develops (132). These MEMRI findings help us understand the pathogenesis of glaucoma and monitor the effects of drug interventions and provide an in vivo global perspective for investigations of the primary visual conduction system in rats. MEMRI is expected to serve as an important complement to examinations of visual function in subjects with glaucoma.

\section{Retinopathy}

MEMRI has been used to observe changes in the function of the retina, degenerative changes in the retina, and diabetic retinopathy. Berkowitz et al. did not detect a significant difference in the signal intensity in the light/dark states between the inner and outer layers of the retina on conventional MRI, but MEMRI revealed that the change in signal intensity between light/dark conditions was significantly greater in the outer layer of the retina than that in the inner layer of the retina, facilitating observations of the physiological response of the normal retina (133). MEMRI was also used to assess changes in retinal function and post-treatment efficacy by measuring ion channel activity (134). In addition to displaying changes in retinal function, MEMRI reveals changes in the retinal structure. In rats with degenerative changes in retinal photoreceptors, MEMRI detected structure changes in the retina layers, and the outer plexiform layer, outer nuclear layer, and photoreceptor inner and outer segment layers disappeared (135). The thickness of the retina and the degree of $\mathrm{Mn}^{2+}$ uptake differ at different stages of degenerative changes due to changes in ion regulation within the retina (136). In addition, excitotoxicity is associated with the pathogenesis of various ocular diseases and the pathogenesis of retinal ischemia. In a glutamate excitotoxic retinal injury model, MEMRI reveals a decrease in the $\mathrm{Mn}^{2+}$ transport function of the visual pathway, and when combined with DTI and optical coherence tomography, MEMRI provides information about temporal and spatial changes in white matter integrity, as well as relationships between changes in eye-brain and structurephysiology relationships in the visual system (137).

Diabetic mice present a gradual decrease in the thickness of the central region of the retina with increasing age (138). $\mathrm{Mn}^{2+}$ uptake in the retinas of these animals is reduced but can return to normal after vascular inhibitor treatment with lipoic acid (139). In streptozotocin-induced diabetic rat retinas, MEMRI detected a decrease in calcium ion activity in the outer layer of the retina 14 days after the onset of early hyperglycemia and decreased activity of the choroid, the latter of which returned to normal after 30 days (140). Similar studies have revealed differences in the retinal uptake of $\mathrm{Mn}^{2+}$ at different intervals in diabetic mouse models. $\mathrm{Mn}^{2+}$ uptake is initially lower than normal in mice at early stages of the disease (diabetes for 1.5-4 months) and then gradually increases (diabetes for more than 5.5 months) (138). Early diabetes had little effect on the axonal transport function, and at week 4, MEMRI did not detect abnormalities in visual conduction pathways from the retina to the lateral geniculate and superior colliculus (141).

\section{BRAIN INJURY}

\section{Stroke}

The ischemic penumbra that forms after stroke is defined as the impaired but rescuable ischemic brain tissue around the irreversibly damaged core region (142). MEMRI shows high signal intensity in the ischemic area of the cerebral cortex, reflecting the intracellular $\mathrm{Ca}^{2+}$ influx caused by hypoxic depolarization. The area with an enhanced $\mathrm{Mn}^{2+}$ signal is the central area of ischemia and is smaller than the area detected using the apparent diffusion coefficient (ADC). MEMRI is expected to become the main imaging method used to detect cerebral ischemia in the hyperacute phase (143). From a few days and a few weeks after stroke, MEMRI showed an increase 
in $\mathrm{Mn}^{2+}$ enhancement in peri-ischemic tissue mainly due to the inflammatory responses of surrounding tissues and the proliferation of reactive astrocytes $(47,100)$. This manifestation indicates nerve repair.

MEMRI has also been used to monitor and assess changes in neurological function after stroke and can facilitate assessment of the extent of the loss of function and recovery after stroke. Most studies use local brain injection of $\mathrm{Mn}^{2+}$ to study changes in neural connections and functions after stroke. After establishing a rat model of stroke induced by unilateral middle cerebral artery occlusion, manganese was injected into the ipsilateral sensorimotor cortex 2 weeks later, and MEMRI showed decreased enhancement in subcortical areas such as the caudate-putamen, $\mathrm{SNc}$, and thalamus (increased R1 values), suggesting disruptions in the neural connections in the motor cortex (45). In addition to local neural connections, distant neural connections are also affected. A stroke in the sensorimotor cortex that is located farther away from the hippocampus has been shown to alter the neural connections between the hippocampus and thalamus as evidenced by impaired $\mathrm{Mn}^{2+}$ transport and $\mathrm{Mn}^{2+}$ aggregation in the thalamus (37). At 10 weeks after unilateral establishment of large-area stroke in rats, the functional connections between the contralateral primary motor cortex (M1) and the ipsilateral sensorimotor cortex region were reduced, which was accompanied by reduced translocation of $\mathrm{Mn}^{2+}$ from the contralateral $\mathrm{M} 1$ to the ipsilateral sensorimotor cortex (24). According to these studies, MEMRI can assess temporal and spatial changes in neurological connections after stroke. Longitudinal MEMRI has been used to dynamically observe the integrity of the post-stroke corticothalamic pathway and is helpful to understanding the recovery of brain function after stroke and to visualize plastic changes in cortical-hypothalamic connections (71).

\section{Traumatic Brain Injury (TBI)}

TBI is the most common cause of long-term disability and death in trauma patients and imposes a substantial socioeconomic and health care burden. Neuroimaging biomarkers provide a method to noninvasively visualize structural and functional abnormalities in the brains of subjects with TBI. For example, DTI is used to observe changes in the white matter microstructure (144), MRI angiography is used to observe changes in cerebral blood flow (145), magnetic resonance spectroscopy (MRS) is used to observe changes in neuronal metabolism (146), and susceptibility-weighted imaging (SWI) has been used to observe micro bleeding in subjects with diffuse axonal injury. MEMRI is also potentially useful for TBI research because MEMRI provides high-contrast and detailed information about structural and functional changes in the brain in vivo, and $\mathrm{Mn}^{2+}$ remains in the body for several days, which is beneficial for continuous and dynamic observations.

The volume of the rat brain was measured after fluid percussion injury using MEMRI. The volumes of the whole brain, hippocampus, and cortex decreased gradually from 1 to 6 months after injury, but changes in $\mathrm{Mn}^{2+}$ enhancement were observed only in the hippocampus. In particular, the enhancement was significantly increased in the DG on the injured side at 1 month post injury, which may represent an active region involved in subacute neuronal remodeling (147). Calcium channel dysfunction is associated with secondary TBI. $\mathrm{Mn}^{2+}$ is a calcium ion analog, and MEMRI has been used to study calcium ion channel-related problems. In the hyperacute phase, MEMRI (SA of $\mathrm{Mn}^{2+}$ through the tail vein) can detect early excitotoxic damage and early signs of $\mathrm{BBB}$ destruction before vasogenic edema; thus, MEMRI allows earlier and more sensitive detection than T2WI. In the subacute phase, MEMRI detects reactive astrocyte proliferation around the lesion (148). MEMRI (intraperitoneal administration of $\mathrm{Mn}^{2+}$ ) has also been used to diagnose explosive blast-induced TBI, and an increase in MEMRI signal intensity serves as a biomarker for mildto-moderate explosive blast-induced TBI (149). In a study of tinnitus caused by explosive blast-induced TBI, MEMRI data showed increased activity along the bilateral auditory pathway and certain peripheral regions in rats with tinnitus compared with that in the age-matched control group (150). In addition to observing changes in TBI, MEMRI has been used to observe changes after TBI treatment. Tang et al. and Jiang et al. used MEMRI to monitor the activity and function of stem cells after neural stem cell transplantation in TBI rats $(151,152)$.

\section{Hypoxic-Ischemic Encephalopathy (HIE)}

Neonatal HIE is a type of hypoxic-ischemic brain damage caused by neonatal asphyxia during the perinatal period, which can cause neurodevelopmental disorders and lead to varying degrees of disability, resulting in high morbidity and mortality rates. After systemic $\mathrm{Mn}^{2+}$ injection into a mild HIE model, MEMRI showed enhanced signals in cerebral cortical lesions, which persisted from acute to late phases. The enhanced signals were associated with increased immunological activity of glutamine synthetase (GS) and manganese superoxide dismutase (Mn-SOD) (these two enzymes are conjugated enzymes that protect against glutamate toxicity and oxidative stress during neurodegeneration), and MEMRI detected late-stage mild HIE in damaged gray matter, which cannot be detected using conventional methods (153). MEMRI also detects neurodegenerative changes caused by HIE. In a neonatal HIE model of 1-week-old rats, ipsilateral lesions did not show $\mathrm{Mn}^{2+}$ enhancement on T1WI, and histology showed no $\mathrm{Mn}$-SOD or GS production in the acute phase (first 2 days). $\mathrm{Mn}^{2+}$ enhancement occurred in the cortex, basal ganglia, and hippocampus in the medium phase (starting from day 3), which was associated with increased local Mn-SOD and GS activity. However, in the late stage, the enhanced region was mainly confined to the basal ganglia and areas around the cortex, and the signal gradually weakened (154). Thus, changes in the activities of the Mn-SOD and GS enzymes can be monitored using MEMRI for early determination of neurodegenerative changes caused by HIE.

Delayed death of neurons and secondary inflammatory reactions occur several days after the onset of neonatal HIE. In another study using the same HIE model of one-weekold rats, MEMRI (intraperitoneal administration of $\mathrm{MnCl}_{2}$ ) showed no increase in enhancement on days 1 and 3 , but $\mathrm{Mn}^{2+}$ enhancement increased in the cortex, hippocampus, and thalamus on day 7. Histology revealed delayed neuronal death 
and inflammation in these areas, and a large number of activated microglia were present in these regions with high enhancement. Based on these findings, late-stage $\mathrm{Mn}^{2+}$ enhancement may be associated with inflammatory processes rather than cell death (155). This group subsequently performed a continuous MEMRI study (1, 3, 7, and 42 days after HIE) and discovered liquefaction on day 42 in areas showing enhancement on day 7 (the hippocampus, thalamus, and basal ganglia), and the main areas with $\mathrm{Mn}^{2+}$ enhancement on day 42 were the calcified areas surrounded by activated microglia and reactive astrocytes in the residual thalamus (156). Meanwhile, anti-inflammatory treatment with doxycycline reduces long-term brain tissue loss and white matter damage after neonatal HIE (157). In some studies, MEMRI and DTI were combined to observe gray and white matter damage in the brain caused by HIE and hyperbaric oxygen therapy (158). MEMRI enables researchers to observe in vivo pathological processes after HIE and to evaluate the efficacy of HIE treatments.

\section{Chemical and Physical Brain Injury}

Chemotherapy can improve the long-term survival rate of patients with cancer, but chemotherapy can also cause brain damage, leading to chemotherapy-related cognitive dysfunction, which is commonly known as chemo brain or chemo fog and is a common side effect of chemotherapy (159). Shortterm memory is significantly impaired by chemotherapy and is often associated with impaired neurogenesis, inflammation, and mitochondrial dysfunction in the hippocampus (160). The chemotherapy-treated mice showed a significant decrease in MEMRI signal intensity in the hippocampal subregions, suggesting a decrease in neuronal activity in this region (161). Resveratrol is a natural polyphenol that prevents cognitive impairment caused by chemotherapy. Resveratrol treatment in mice with chemotherapy-induced brain injury improves chemotherapy-induced cognitive impairment and leads to a significantly increased intensity of the MEMRI signal in the prefrontal cortex, whole hippocampus, and the cortex of the CA3 hippocampal subregion (162). Based on these findings, MEMRI is a useful tool to assess the conditions of chemotherapyinduced brain injury and the efficacy of treatments. In addition to brain damage caused by active chemotherapy, passive brain damage is caused by poisoning, such as pesticide poisoning. Organic phosphates are widely used as pesticides in agriculture. Ingestion of organic phosphates causes poisoning or even death, and chronic intake causes neurological damage. Hernandez et al. studied the effects of chlorpyrifos on axonal transport in rat brains and found that repeated exposure to chlorpyrifos resulted in a sustained change in axonal transport in the brains of living mammals, with reduced transport of $\mathrm{Mn}^{2+}$ from the optic nerve to the superior colliculus (4). Repeated exposure to diisopropylfluorophosphate also resulted in destruction of the structure of myelinated axons and a sustained decrease in axonal transport in the rat brain (163).

MEMRI is also used in radiation brain injury research, particularly for subjects with CNS diseases induced by prenatal radiation exposure. $\mathrm{Mn}^{2+}$ uptake was decreased in the rat brain in the radiation-exposed group at 2 weeks after birth and was mainly associated with decreased cell viability (apoptotic alteration) and decreased cell density after prenatal radiation exposure (164). In another study, 3-week-old rats exposed to prenatal radiation showed a decrease in brain volume, significant expansion of the lateral ventricles, a decrease in the MEMRIenhanced area in the hippocampus, and disappearance of the MEMRI signal in the CA1/2 region due to destruction of the CA1/2 pyramidal cell layer by invading ectopic cell clusters. However, $\mathrm{Mn}^{2+}$ enhancement was still present in the CA3 and DG regions, mainly due to glial cell activation, but was below normal levels (165). In a study of tumor radiotherapy, MEMRI detected cellular changes at an early stage $(24 \mathrm{~h})$ (166). Thus, MEMRI provides valuable information regarding neurological damage and functional changes after radiationinduced brain injury.

\section{Epilepsy}

Animal models of temporal lobe epilepsy include kainic acid (KA)-, pilocarpine-, and pentylenetetrazol-induced epilepsy models, which are divided into an acute phase and a latent phase. Different stages of disease development are associated with different neurobiological changes, such as hippocampal sclerosis, mossy fiber sprouting, inflammation, and neurodegeneration (114).

In a KA-induced rat model, an MEMRI (administration of $\mathrm{Mn}^{2+}$ through the tail vein) study showed an increase in the enhancement of the CA3 pyramidal cell layer after KA treatment that was associated with astrocyte proliferation, and the enhancement on MEMRI was reduced after treatment with the L-type calcium channel blocker diltiazem due to focal edema and decreased neuronal swelling (167). When pilocarpine-induced temporal lobe epilepsy in rats lasted for $30 \mathrm{~min}$, a decrease in the $\mathrm{Mn}^{2+}$-enhanced signal was detected in the DG and CA3 regions (compared to the control group), and this reduction was associated with cerebral edema (168) rather than apoptosis (169). Furthermore, 3-5 days after $\mathrm{Mn}^{2+}$ injection into the entorhinal cortex, the MEMRI signals in the ipsilateral and contralateral hippocampal DG and CA3 regions gradually increased, and this enhancement was associated with histologically confirmed mossy fiber sprouting (36). In the chronic phase of epilepsy (2 months after KA induction), MEMRI revealed increases in the signal intensity of the CA1 region and DG after SA of $\mathrm{Mn}^{2+}$, but the increase was not obvious at early time points (4 days or less). The changes in the MEMRI signal in the hippocampus were attributed to an increase in axonal density following mossy fiber sprouting rather than neurodegeneration or proliferation of astrocytes or microglia (170). Direct injections of $\mathrm{Mn}^{2+}$ into the lateral ventricle of a rat model of temporal lobe epilepsy induced by $\mathrm{KA}$ revealed a gradual increase in the enhancement of the CA3, CA1, and DG regions in the hippocampus from $48 \mathrm{~h}$ to 6 weeks, but the enhancement was negatively correlated with the frequency of seizures (70). Similar studies have reported a significant reduction in $\mathrm{Mn}^{2+}$ enhancement in the early stages of epilepsy and gradual recovery of $\mathrm{Mn}^{2+}$ enhancement in the latent and chronic phases (171). According to these studies, the features of changes observed in different stages of MEMRI reflect 
pathophysiological changes during the development of epilepsy, including cell damage and repair, as well as changes in neuronal activity. Systemic intravenous infusion of mesenchymal stem cells in rats during epilepsy onset can reduce the occurrence of epileptic episodes, and the degree of $\mathrm{Mn}^{2+}$ enhancement in the hippocampus changed from high to low, which was related to inhibition of mossy fiber sprouting (172). Researchers postulate that changes in MEMRI signals will be used as an index to evaluate treatment efficacy.

\section{Neuroinflammation and Drug Abuse}

Neuroinflammation not only plays a role in CNS damage involving infection and trauma but also plays a key role in autoimmunity and neurodegenerative diseases (173). MEMRI also has important application value in neuroinflammation. MEMRI can be used in the following cases and in diseases with neuroinflammation characteristics such as MS, optic neuritis, and post-stroke neuroinflammation. MEMRI can reflect brain pathology during progressive HIV-1 infection in mice, and the signal intensity corresponded to the levels of HIV1 infection, neuroinflammation, and neuronal injury (174). In addition, MEMRI is also used to detect changes in neuronal activity caused by neuroinflammation in metabolic diseases. Thinschmidt et al. found a significant reduction in basal hypothalamic neuronal activity in 8-month-old Ins $2^{\text {Akita }}$ diabetic mice using MEMRI (175).

Drug abuse (including alcohol and nicotine) is an important health issue among society. MEMRI is sensitive to neuronal activities affected by drug abuse and is a very useful for understanding the mechanism and treatment of drug abuse. Dudek et al. demonstrated the extensive brain activation associated with voluntary alcohol drinking in rats using MEMRI, which may be a useful imaging tool for investigating modulation of alcohol-related brain activation by drugs (176). They also found that the caudal linear nucleus controls alcohol preferences and consumption in alcohol-preferring rats, and its activity can be revealed by MEMRI (177). In addition, MEMRI mapping may be a useful translational tool for developing and evaluating pharmacotherapies for alcohol use disorders (178). Smoking is a major public health problem. MEMRI can be used as a non-invasive biomarker to monitor acute and chronic nicotine exposure-induced neuronal activities in cortical and subcortical regions (179).

\section{Spinal Cord Injury}

Spinal cord injury (SCI) is another serious CNS disease with high mortality and disability rates. MRI has important application value in SCI. MEMRI has been used to assess the type, extent, and dysfunction conditions of SCI and to track the integrity of the corticospinal tract $(48,59,64)$. The $\mathrm{Mn}^{2+}$ signal intensity is significantly correlated with motor function, and no enhancement is observed at the injury site or at the caudal end (63). By comparing changes in spinal axonal transport rates, nerve regeneration was studied in vivo at different stages (65). MEMRI was correlated with and used to determine the severity of SCI. The signal intensity of MEMRI (lateral ventricle $\mathrm{MnCl}_{2}$ injection) was positively correlated with the myelin load in the acute phase of SCI (66). In the rat spinal cord with electrical injury, MEMRI (lateral ventricle $\mathrm{MnCl}_{2}$ injection) showed an interruption in spinal cord enhancement in the thoracic region, and histology confirmed a more significant reduction in the number of neurons in the ventral horn than that in the dorsal horn (67). MEMRI has also been used to monitor the efficacy of SCI treatment. The MEMRI signal intensity (cisterna magna $\mathrm{MnCl}_{2}$ injection) was significantly higher in rats with acute SCI than that in the control group after short-term erythropoietin treatment. The intensity of the MEMRI signal was significantly correlated with the recovery of function in rats, which is potentially useful for early monitoring and treatment (62). Similarly, MEMRI showed a significant increase in relative signal intensity after SCI was treated with cell transplantation, suggesting the repair and regeneration of axons $(68,69)$.

\section{CONCLUSIONS}

This review describes the applications of MEMRI in CNS diseases and provides a visual approach to study the pathophysiological processes of such diseases. $\mathrm{Mn}^{2+}$ is a calcium ion analog that enters cells and represents a unique functional imaging tool used to visualize changes in vivo, allowing the detection of subtle, early changes in the body. MEMRI has been used to assess cellular/structural integrity, functional activity, and neural connectivity, thus enabling early detection of neuronal function, the intracellular ion balance, and axonal transport. MEMRI also helps determine disease severity and evaluate treatment efficacy.

As in-depth studies are conducted, MEMRI will have increasing applications in preclinical research on the nervous system, which may reveal the relationship between neurological function and injury and between plasticity and repair. The combination of MEMRI with other imaging methods will provide complementary techniques to reveal the pathophysiological processes of diseases. However, the toxic effects of $\mathrm{MnCl}_{2}$ limit the use of MEMRI in humans, and only a few studies have used the Food and Drug Administration (FDA)approved agent mangafodipir in humans. When conditions permit, local administration of a low dose is the preferred method due to reduced toxic effects. The sensitivity of PET is much higher than that of MRI, and PET uses a lower dose of manganese for imaging. In particular, the emergence of Mn-PET/MRI will be beneficial for clinical applications of $\mathrm{Mn}^{2+}(180,181)$. Further developments in material science are expected to produce safe manganesecontaining contrast agents. Together with highly sensitive MRI using lower doses of $\mathrm{Mn}^{2+}$, these contrast agents will provide broad prospects and endless possibilities for MEMRI clinical applications.

\section{AUTHOR CONTRIBUTIONS}

JY proposed the topic and wrote the manuscript. QL edited the manuscript. 


\section{FUNDING}

This study was supported by the National Natural Science Foundation of China (Grant No. 81703155), the Yunnan Applied

\section{REFERENCES}

1. Schaeffer DJ, Johnston KD, Gilbert KM, Gati JS, Menon RS, Everling S. In vivo manganese tract tracing of frontal eye fields in rhesus macaques with ultra-high field MRI: comparison with DWI tractography. Neuroimage. (2018) 181:211-8. doi: 10.1016/j.neuroimage.2018.06.072

2. Kim J, Choi IY, Michaelis ML, Lee P. Quantitative in vivo measurement of early axonal transport deficits in a triple transgenic mouse model of Alzheimer's disease using manganese-enhanced MRI. Neuroimage. (2011) 56:1286-92. doi: 10.1016/j.neuroimage.2011.02.039

3. Lin TH, Kim JH, Perez-Torres C, Chiang CW, Trinkaus K, Cross AH, et al. Axonal transport rate decreased at the onset of optic neuritis in EAE mice. Neuroimage. (2014) 100:244-53. doi: 10.1016/j.neuroimage.2014.06.009

4. Hernandez CM, Beck WD, Naughton SX, Poddar I, Adam BL, Yanasak N, et al. Repeated exposure to chlorpyrifos leads to prolonged impairments of axonal transport in the living rodent brain. Neurotoxicology. (2015) 47:17-26. doi: 10.1016/j.neuro.2015.01.002

5. Cloyd RA, Koren SA, Abisambra JF. Manganese-enhanced magnetic resonance imaging: overview and central nervous system applications with a focus on neurodegeneration. Front Aging Neurosci. (2018) 10:403. doi: 10.3389/fnagi.2018.00403

6. Bedenk BT, Almeida-Correa S, Jurik A, Dedic N, Grunecker B, Genewsky AJ, et al. $\mathrm{Mn}(2+)$ dynamics in manganese-enhanced MRI (MEMRI): Cav1.2 channel-mediated uptake and preferential accumulation in projection terminals. Neuroimage. (2018) 169:374-82. doi: 10.1016/j.neuroimage.2017.12.054

7. Drapeau P, Nachshen DA. Manganese fluxes and manganese-dependent neurotransmitter release in presynaptic nerve endings isolated from rat brain. J Physiol. (1984) 348:493-510. doi: 10.1113/jphysiol.1984.sp015121

8. Narita K, Kawasaki F, Kita H. Mn and Mg influxes through Ca channels of motor nerve terminals are prevented by verapamil in frogs. Brain Res. (1990) 510:289-95. doi: 10.1016/0006-8993(90)91379-U

9. Pautler RG, Koretsky AP. Tracing odor-induced activation in the olfactory bulbs of mice using manganese-enhanced magnetic resonance imaging. Neuroimage. (2002) 16:441-8. doi: 10.1006/nimg.2002.1075

10. Takeda A. Manganese action in brain function. Brain Res Brain Res Rev. (2003) 41:79-87. doi: 10.1016/S0165-0173(02)00234-5

11. Aschner M, Gannon M. Manganese (Mn) transport across the rat bloodbrain barrier: saturable and transferrin-dependent transport mechanisms. Brain Res Bull. (1994) 33:345-9. doi: 10.1016/0361-9230(94)90204-6

12. Crossgrove J, Zheng W. Manganese toxicity upon overexposure. NMR Biomed. (2004) 17:544-53. doi: 10.1002/nbm.931

13. $\mathrm{Au} \mathrm{C}$, Benedetto $\mathrm{A}$, Aschner $\mathrm{M}$. Manganese transport in eukaryotes: the role of DMT1. Neurotoxicology. (2008) 29:56976. doi: 10.1016/j.neuro.2008.04.022

14. Watanabe T, Frahm J, Michaelis T. Functional mapping of neural pathways in rodent brain in vivo using manganese-enhanced threedimensional magnetic resonance imaging. NMR Biomed. (2004) 17:55468. doi: $10.1002 / \mathrm{nbm} .937$

15. Silva AC, Lee JH, Wu CW, Tucciarone J, Pelled G, Aoki I, et al. Detection of cortical laminar architecture using manganese-enhanced MRI. J Neurosci Methods. (2008) 167:246-57. doi: 10.1016/j.jneumeth.2007.08.020

16. Chuang $\mathrm{KH}$, Belluscio $\mathrm{L}$, Koretsky AP. In vivo detection of individual glomeruli in the rodent olfactory bulb using manganese enhanced MRI. Neuroimage. (2010) 49:1350-6. doi: 10.1016/j.neuroimage.2009. 09.060

17. Gutman DA, Magnuson M, Majeed W, Keifer OPJr, Davis M, Ressler KJ, et al. Mapping of the mouse olfactory system with manganese-enhanced magnetic resonance imaging and diffusion tensor imaging. Brain Struct Funct. (2013) 218:527-37. doi: 10.1007/s00429-012-0413-6
Basic Research Projects-Kunming Medical University Joint Special Project [Grant No. 2017FE468 (-071)], Yunnan Health Training Project of High Level Talents (H-2017005), and the Education Department of Yunnan Province (2019J1280).

18. Sajja BR, Bade AN, Zhou B, Uberti MG, Gorantla S, Gendelman $\mathrm{HE}$, et al. Generation and disease model relevance of a manganese enhanced magnetic resonance imaging-based NOD/scid-IL2Rgammac(null) mouse brain atlas. J Neuroimmune Pharmacol. (2016) 11:133-41. doi: 10.1007/s11481-015-9635-8

19. Pautler RG, Mongeau R, Jacobs RE. In vivo trans-synaptic tract tracing from the murine striatum and amygdala utilizing manganese enhanced MRI (MEMRI). Magn Reson Med. (2003) 50:33-9. doi: 10.1002/mrm.10498

20. Chan $\mathrm{KC}, \mathrm{Wu} \mathrm{EX}$. In vivo manganese-enhanced MRI for visuotopic brain mapping. Conf Proc IEEE Eng Med Biol Soc. (2012) 2012:227982. doi: 10.1109/EMBC.2012.6346417

21. Bissig D, Berkowitz BA. Manganese-enhanced MRI of layer-specific activity in the visual cortex from awake and free-moving rats. Neuroimage. (2009) 44:627-35. doi: 10.1016/j.neuroimage.2008.10.013

22. Chuang KH, Lee JH, Silva AC, Belluscio L, Koretsky AP. Manganese enhanced MRI reveals functional circuitry in response to odorant stimuli. Neuroimage. (2009) 44:363-72. doi: 10.1016/j.neuroimage.2008.08.046

23. Fa Z, Zhang $\mathrm{P}$, Huang F, Li P, Zhang $\mathrm{R}, \mathrm{Xu} \mathrm{R}$, et al. Activityinduced manganese-dependent functional MRI of the rat visual cortex following intranasal manganese chloride administration. Neurosci Lett. (2010) 481:110-4. doi: 10.1016/j.neulet.2010.06.063

24. Van Meer MP, Van Der Marel K, Otte WM, Berkelbach Van Der Sprenkel JW, Dijkhuizen RM. Correspondence between altered functional and structural connectivity in the contralesional sensorimotor cortex after unilateral stroke in rats: a combined resting-state functional MRI and manganese-enhanced MRI study. J Cereb Blood Flow Metab. (2010) 30:170711. doi: $10.1038 / \mathrm{jcbfm} .2010 .124$

25. Lehallier B, Rampin O, Saint-Albin A, Jerome N, Ouali C, Maurin $\mathrm{Y}$, et al. Brain processing of biologically relevant odors in the awake rat, as revealed by manganese-enhanced MRI. PLoS ONE. (2012) 7:e48491. doi: 10.1371/journal.pone.0048491

26. Gálosi R, Szalay C, Aradi M, Perlaki G, Pál J, Steier R, et al. Identifying non-toxic doses of manganese for manganese-enhanced magnetic resonance imaging to map brain areas activated by operant behavior in trained rats. Magn Reson Imaging. (2017) 37:122-33. doi: 10.1016/j.mri.2016.11.017

27. Pautler RG, Silva AC, Koretsky AP. In vivo neuronal tract tracing using manganese-enhanced magnetic resonance imaging. Magn Reson Med. (1998) 40:740-8. doi: 10.1002/mrm.1910400515

28. Murayama Y, Weber B, Saleem KS, Augath M, Logothetis NK. Tracing neural circuits in vivo with Mn-enhanced MRI. Magn Reson Imaging. (2006) 24:349-58. doi: 10.1016/j.mri.2005.12.031

29. Massaad CA, Pautler RG. Manganese-Enhanced Magnetic Resonance Imaging (MEMRI). In: Modo M, Bulte JWM, editors. Magnetic Resonance Neuroimaging: Methods and Protocols. Totowa, NJ: Humana Press (2011). p. $145-74$.

30. Auffret M, Samim I, Lepore M, Gruetter R, Just N. Quantitative activityinduced manganese-dependent MRI for characterizing cortical layers in the primary somatosensory cortex of the rat. Brain Struct Funct. (2016) 221:695-707. doi: 10.1007/s00429-014-0933-3

31. Schroeder MP, Weiss C, Procissi D, Wang L, Disterhoft JF. Activity-induced manganese-dependent MRI (AIM-MRI) and functional MRI in awake rabbits during somatosensory stimulation. Neuroimage. (2016) 126:7280. doi: 10.1016/j.neuroimage.2015.11.033

32. Aoki I, Tanaka C, Takegami T, Ebisu T, Umeda M, Fukunaga M, et al. Dynamic activity-induced manganese-dependent contrast magnetic resonance imaging (DAIM MRI). Magn Reson Med. (2002) 48:92733. doi: 10.1002/mrm.10320

33. Aoki I, Wu YJ, Silva AC, Lynch RM, Koretsky AP. In vivo detection of neuroarchitecture in the rodent brain using manganese-enhanced MRI. Neuroimage. (2004) 22:1046-59. doi: 10.1016/j.neuroimage.2004.03.031 
34. Watanabe T, Radulovic J, Spiess J, Natt O, Boretius S, Frahm J, et al. In vivo 3D MRI staining of the mouse hippocampal system using intracerebral injection of $\mathrm{MnCl} 2$. Neuroimage. (2004) 22:8607. doi: 10.1016/j.neuroimage.2004.01.028

35. Chen CC, Zechariah A, Hsu YH, Chen HW, Yang LC, Chang C. Neuroaxonal ion dyshomeostasis of the normal-appearing corpus callosum in experimental autoimmune encephalomyelitis. Exp Neurol. (2008) 210:322-30. doi: 10.1016/j.expneurol.2007.11.008

36. Nairismagi J, Pitkanen A, Narkilahti S, Huttunen J, Kauppinen RA, Grohn OH. Manganese-enhanced magnetic resonance imaging of mossy fiber plasticity in vivo. Neuroimage. (2006) 30:130-5. doi: 10.1016/j.neuroimage.2005.09.007

37. Baumgartner P, El Amki M, Bracko O, Luft AR, Wegener S. Sensorimotor stroke alters hippocampo-thalamic network activity. Sci Rep. (2018) 8:15770. doi: 10.1038/s41598-018-34002-9

38. Sourani D, Eitan R, Gordon N, Goelman G. The habenula couples the dopaminergic and the serotonergic systems: application to depression in Parkinson's disease. Eur J Neurosci. (2012) 36:2822-9. doi: 10.1111/j.1460-9568.2012.08200.x

39. Medina CS, Biris O, Falzone TL, Zhang X, Zimmerman AJ, Bearer EL. Hippocampal to basal forebrain transport of $\mathrm{Mn}(2+)$ is impaired by deletion of KLC1, a subunit of the conventional kinesin microtubule-based motor. Neuroimage. (2017) 145:44-57. doi: 10.1016/j.neuroimage.2016.09.035

40. Demain B, Davoust C, Plas B, Bolan F, Boulanouar K, Renaud L, et al. Corticospinal Tract Tracing in the Marmoset with a Clinical WholeBody 3T Scanner Using Manganese-Enhanced MRI. PLoS ONE. (2015) 10:e0138308. doi: 10.1371/journal.pone.0138308

41. Zhang X, Bearer EL, Boulat B, Hall FS, Uhl GR, Jacobs RE. Altered neurocircuitry in the dopamine transporter knockout mouse brain. PLoS ONE. (2010) 5:e11506. doi: 10.1371/journal.pone.0011506

42. Bearer EL, Zhang X, Janvelyan D, Boulat B, Jacobs RE. Reward circuitry is perturbed in the absence of the serotonin transporter. Neuroimage. (2009) 46:1091-104. doi: 10.1016/j.neuroimage.2009.03.026

43. Li Y, Fang F, Wang X, Lei H. Neuronal projections from ventral tegmental area to forebrain structures in rat studied by manganeseenhanced magnetic resonance imaging. Magn Reson Imaging. (2009) 27:2939. doi: 10.1016/j.mri.2008.07.011

44. Simmons JM, Saad ZS, Lizak MJ, Ortiz M, Koretsky AP, Richmond BJ. Mapping prefrontal circuits in vivo with manganese-enhanced magnetic resonance imaging in monkeys. J Neurosci. (2008) 28:7637-47. doi: 10.1523/JNEUROSCI.1488-08.2008

45. Van Der Zijden JP, Wu O, Van Der Toorn A, Roeling TP, Bleys RL, Dijkhuizen RM. Changes in neuronal connectivity after stroke in rats as studied by serial manganese-enhanced MRI. Neuroimage. (2007) 34:16507. doi: 10.1016/j.neuroimage.2006.11.001

46. Van Der Zijden JP, Van Der Toorn A, Van Der Marel K, Dijkhuizen RM. Longitudinal in vivo MRI of alterations in perilesional tissue after transient ischemic stroke in rats. Exp Neurol. (2008) 212:20712. doi: 10.1016/j.expneurol.2008.03.027

47. Hao XZ, Yin LK, Zhang XX, Tian JQ, Li CC, Feng XY, et al. Combining systemic and stereotactic MEMRI to detect the correlation between gliosis and neuronal connective pathway at the chronic stage after stroke. J Neuroinflammation. (2016) 13:156. doi: 10.1186/s12974-0160622-7

48. Bilgen M. Imaging corticospinal tract connectivity in injured rat spinal cord using manganese-enhanced MRI. BMC Med Imaging. (2006) 6:15. doi: 10.1186/1471-2342-6-15

49. Bilgen M, Peng W, Al-Hafez B, Dancause N, He YY, Cheney PD. Electrical stimulation of cortex improves corticospinal tract tracing in rat spinal cord using manganese-enhanced MRI. J Neurosci Methods. (2006) 156:1722. doi: 10.1016/j.jneumeth.2006.02.001

50. Gallagher JJ, Zhang X, Ziomek GJ, Jacobs RE, Bearer EL. Deficits in axonal transport in hippocampal-based circuitry and the visual pathway in APP knock-out animals witnessed by manganese enhanced MRI. Neuroimage. (2012) 60:1856-66. doi: 10.1016/j.neuroimage.2012.01.132

51. Daoust A, Bohic S, Saoudi Y, Debacker C, Gory-Faure S, Andrieux A, et al. Neuronal transport defects of the MAP6 KO mouse - a model of schizophrenia - and alleviation by Epothilone
D treatment, as observed using MEMRI. Neuroimage. (2014) 96:133-42. doi: 10.1016/j.neuroimage.2014.03.071

52. Tucciarone J, Chuang KH, Dodd SJ, Silva A, Pelled G, Koretsky AP. Layer specific tracing of corticocortical and thalamocortical connectivity in the rodent using manganese enhanced MRI. Neuroimage. (2009) 44:92331. doi: 10.1016/j.neuroimage.2008.07.036

53. Hsu YH, Chen CC, Zechariah A, Yen CC, Yang LC, Chang C. Neuronal dysfunction of a long projecting multisynaptic pathway in response to methamphetamine using manganese-enhanced MRI. Psychopharmacology. (2008) 196:543-53. doi: 10.1007/s00213-007-0990-x

54. Chiu CH, Siow TY, Weng SJ, Hsu YH, Huang YS, Chang KW, et al. Effect of MDMA-induced axotomy on the dorsal raphe forebrain tract in rats: an in vivo manganese-enhanced magnetic resonance imaging study. PLoS ONE. (2015) 10:e0138431. doi: 10.1371/journal.pone.0138431

55. Sun N, Li Y, Tian S, Lei Y, Zheng J, Yang J, et al. Dynamic changes in orbitofrontal neuronal activity in rats during opiate administration and withdrawal. Neuroscience. (2006) 138:77-82. doi: 10.1016/j.neuroscience.2005.10.034

56. Leergaard TB, Bjaalie JG, Devor A, Wald LL, Dale AM. In vivo tracing of major rat brain pathways using manganese-enhanced magnetic resonance imaging and three-dimensional digital atlasing. Neuroimage. (2003) 20:1591-600. doi: 10.1016/j.neuroimage.2003.07.009

57. Bilgen M, Dancause N, Al-Hafez B, He YY, Malone TM. Manganeseenhanced MRI of rat spinal cord injury. Magn Reson Imaging. (2005) 23:82932. doi: 10.1016/j.mri.2005.06.004

58. Huereca DJ, Bakoulas KA, Ghoddoussi F, Berkowitz BA, Holt AG, Mueller PJ. Development of manganese-enhanced magnetic resonance imaging of the rostral ventrolateral medulla of conscious rats: importance of normalization and comparison with other regions of interest. NMR Biomed. (2018) 31:e3887. doi: 10.1002/nbm.3887

59. Bonny JM, Mailly P, Renou JP, Orsal D, Benmoussa A, Stettler O. Analysis of laminar activity in normal and injured rat spinal cord by manganese enhanced MRI. Neuroimage. (2008) 40:1542-51. doi: 10.1016/j.neuroimage.2008.01.050

60. Liu CH, D'arceuil HE, De Crespigny AJ. Direct CSF injection of $\mathrm{MnCl}(2)$ for dynamic manganese-enhanced MRI. Magn Reson Med. (2004) 51:97887. doi: $10.1002 / \mathrm{mrm} .20047$

61. Cha M, Lee K, Won JS, Lee BH. Manganese-enhanced magnetic resonance imaging of the spinal cord in rats with formalin-induced pain. Neurosci Res. (2019) 149:14-21. doi: 10.1016/j.neures.2019.01.007

62. Freitag MT, Marton G, Pajer K, Hartmann J, Walder N, Rossmann M, et al. Monitoring of short-term erythropoietin therapy in rats with acute spinal cord injury using manganese-enhanced magnetic resonance imaging. J Neuroimaging. (2015) 25:582-9. doi: 10.1111/jon.12202

63. Walder N, Petter-Puchner AH, Brejnikow M, Redl H, Essig M, Stieltjes B. Manganese enhanced magnetic resonance imaging in a contusion model of spinal cord injury in rats: correlation with motor function. Invest Radiol. (2008) 43:277-83. doi: 10.1097/RLI.0b013e318162f1bd

64. Stieltjes B, Klussmann S, Bock M, Umathum R, Mangalathu J, Letellier E, et al. Manganese-enhanced magnetic resonance imaging for in vivo assessment of damage and functional improvement following spinal cord injury in mice. Magn Reson Med. (2006) 55:1124-31. doi: 10.1002/mrm. 20888

65. Martirosyan NL, Bennett KM, Theodore N, Preul MC. Manganese-enhanced magnetic resonance imaging in experimental spinal cord injury: correlation between T1-weighted changes and $\mathrm{Mn}(2+)$ concentrations. Neurosurgery. (2010) 66:131-6. doi: 10.1227/01.NEU.0000361997.08116.96

66. Martirosyan NL, Turner GH, Kaufman J, Patel AA, Belykh E, Kalani MY, et al. Manganese-enhanced MRI offers correlation with severity of spinal cord injury in experimental models. Open Neuroimag J. (2016) 10:13947. doi: 10.2174/1874440001610010139

67. Seo $\mathrm{CH}$, Jeong JH, Lee DH, Kang TC, Jin ES, Lee DH, et al. Radiological and pathological evaluation of the spinal cord in a rat model of electrical injury-induced myelopathy. Burns. (2012) 38:106671. doi: 10.1016/j.burns.2012.02.016

68. Suh HI, Min J, Choi KW, Kim KS, Jeon SR. Axonal regeneration effects of Wnt3a-secreting fibroblast transplantation in spinal cord-injured rats. Acta Neurochir. (2011) 153:1003-10. doi: 10.1007/s00701-011-0945-1 
69. Park JH, Min J, Baek SR, Kim SW, Kwon IK, Jeon SR. Enhanced neuroregenerative effects by scaffold for the treatment of a rat spinal cord injury with Wnt3a-secreting fibroblasts. Acta Neurochir. (2013) 155:80916. doi: 10.1007/s00701-013-1663-7

70. Dedeurwaerdere S, Fang K, Chow M, Shen YT, Noordman I, Van Raay L, et al. Manganese-enhanced MRI reflects seizure outcome in a model for mesial temporal lobe epilepsy. Neuroimage. (2013) 68:308. doi: 10.1016/j.neuroimage.2012.11.054

71. Soria G, Wiedermann D, Justicia C, Ramos-Cabrer P, Hoehn M. Reproducible imaging of rat corticothalamic pathway by longitudinal manganese-enhanced MRI (L-MEMRI). Neuroimage. (2008) 41:66874. doi: 10.1016/j.neuroimage.2008.03.018

72. Roth TL, Nayak D, Atanasijevic T, Koretsky AP, Latour LL, Mcgavern DB. Transcranial amelioration of inflammation and cell death after brain injury. Nature. (2014) 505:223-8. doi: 10.1038/nature12808

73. Atanasijevic T, Bouraoud N, Mcgavern DB, Koretsky AP. Transcranial manganese delivery for neuronal tract tracing using MEMRI. Neuroimage. (2017) 156:146-54. doi: 10.1016/j.neuroimage.2017.05.025

74. Chuang $\mathrm{KH}$, Koretsky AP. Accounting for nonspecific enhancement in neuronal tract tracing using manganese enhanced magnetic resonance imaging. Magn Reson Imaging. (2009) 27:594600. doi: 10.1016/j.mri.2008.10.006

75. Yang J, Li Q, Wang M, Cao X, Ding Y, Wang G, et al. Semiquantitative assessment of optic nerve injury using manganese-enhanced MRI. Jpn J Radiol. (2016) 34:356-65. doi: 10.1007/s11604-016-0533-7

76. Tang Z, Wu L, Xiao Z, Feng X, Sun X, Tang W, et al. Manganese-enhanced MRI (ME MRI) in evaluation of the auditory pathway in an experimental rat model. NMR Biomed. (2017) 30. doi: 10.1002/nbm.3677

77. Aschner M, Guilarte TR, Schneider JS, Zheng W. Manganese: recent advances in understanding its transport and neurotoxicity. Toxicol Appl Pharmacol. (2007) 221:131-47. doi: 10.1016/j.taap.2007.03.001

78. Bornhorst J, Wehe CA, Huwel S, Karst U, Galla HJ, Schwerdtle T. Impact of manganese on and transfer across blood-brain and bloodcerebrospinal fluid barrier in vitro. J Biol Chem. (2012) 287:1714051. doi: 10.1074/jbc.M112.344093

79. Sudarshana DM, Nair G, Dwyer JT, Dewey B, Steele SU, Suto DJ, et al. Manganese-Enhanced MRI of the Brain in Healthy Volunteers. AJNR Am J Neuroradiol. (2019) 40:1309-16. doi: 10.3174/ajnr.A6152

80. Qiu LR, Fernandes DJ, Szulc-Lerch KU, Dazai J, Nieman BJ, Turnbull $\mathrm{DH}$, et al. Mouse MRI shows brain areas relatively larger in males emerge before those larger in females. Nat Commun. (2018) 9:2615. doi: 10.1038/s41467-018-04921-2

81. Lehallier B, Coureaud G, Maurin Y, Bonny JM. Effects of manganese injected into rat nostrils: implications for in vivo functional study of olfaction using MEMRI. Magn Reson Imaging. (2012) 30:62-9. doi: 10.1016/j.mri.2011.08.009

82. Foster ML, Rao DB, Francher T, Traver S, Dorman DC. Olfactory toxicity in rats following manganese chloride nasal instillation: a pilot study. Neurotoxicology. (2018) 64:284-90. doi: 10.1016/j.neuro.2017.09.004

83. Thuen M, Berry M, Pedersen TB, Goa PE, Summerfield M, Haraldseth $\mathrm{O}$, et al. Manganese-enhanced MRI of the rat visual pathway: acute neural toxicity, contrast enhancement, axon resolution, axonal transport, and clearance of $\mathrm{Mn}(2+)$. J Magn Reson Imaging. (2008) 28:85565. doi: 10.1002/jmri.21504

84. Liang S, Liang M, Zhu Y, Cheng J, Yang Z. The distribution of Mn2+ in rabbit eyes after topical administration for manganese-enhanced MRI. Int J Clin Exp Pathol. (2015) 8:836-41.

85. Sun SW, Campbell B, Lunderville C, Won E, Liang HF. Noninvasive topical loading for manganese-enhanced MRI of the mouse visual system. Invest Ophthalmol Vis Sci. (2011) 52:3914-20. doi: 10.1167/iovs.10-6363

86. Sun SW, Thiel T, Liang HF. Impact of repeated topical-loaded manganeseenhanced MRI on the mouse visual system. Invest Ophthalmol Vis Sci. (2012) 53:4699-709. doi: 10.1167/iovs.12-9715

87. Lindsey JD, Scadeng M, Dubowitz DJ, Crowston JG, Weinreb RN. Magnetic resonance imaging of the visual system in vivo: transsynaptic illumination of V1 and V2 visual cortex. Neuroimage. (2007) 34:161926. doi: 10.1016/j.neuroimage.2006.07.048
88. Lindsey JD, Grob SR, Scadeng M, Duong-Polk K, Weinreb RN. Ocular integrity following manganese labeling of the visual system for MRI. Magn Reson Imaging. (2013) 31:865-74. doi: 10.1016/j.mri.2012.11.012

89. Chen P, Bornhorst J, Aschner M. Manganese metabolism in humans. Front Biosci. (2018) 23:1655-79. doi: 10.2741/4665

90. Malheiros JM, Paiva FF, Longo BM, Hamani C, Covolan L. Manganeseenhanced MRI: biological applications in neuroscience. Front Neurol. (2015) 6:161. doi: 10.3389/fneur.2015.00161

91. Bock NA, Paiva FF, Silva AC. Fractionated manganese-enhanced MRI. NMR Biomed. (2008) 21:473-8. doi: 10.1002/nbm.1211

92. Grunecker B, Kaltwasser SF, Peterse Y, Samann PG, Schmidt MV, Wotjak $\mathrm{CT}$, et al. Fractionated manganese injections: effects on MRI contrast enhancement and physiological measures in C57BL/6 mice. NMR Biomed. (2010) 23:913-21. doi: 10.1002/nbm.1508

93. Eschenko O, Canals S, Simanova I, Beyerlein M, Murayama Y, Logothetis NK. Mapping of functional brain activity in freely behaving rats during voluntary running using manganese-enhanced MRI: implication for longitudinal studies. Neuroimage. (2010) 49:2544-55. doi: 10.1016/j.neuroimage.2009.10.079

94. Sepulveda MR, Dresselaers T, Vangheluwe P, Everaerts W, Himmelreich U, Mata AM, et al. Evaluation of manganese uptake and toxicity in mouse brain during continuous $\mathrm{MnCl} 2$ administration using osmotic pumps. Contrast Media Mol Imaging. (2012) 7:426-34. doi: 10.1002/cmmi.1469

95. Poole DS, Doorenweerd N, Plomp JJ, Mahfouz A, Reinders MJT, Van Der Weerd L. Continuous infusion of manganese improves contrast and reduces side effects in manganese-enhanced magnetic resonance imaging studies. Neuroimage. (2017) 147:1-9. doi: 10.1016/j.neuroimage.2016.09.030

96. Chandra A, Dervenoulas G, Politis M. Magnetic resonance imaging in Alzheimer's disease and mild cognitive impairment. J Neurol. (2019) 266:1293-302. doi: 10.1007/s00415-018-9016-3

97. Fontaine SN, Ingram A, Cloyd RA, Meier SE, Miller E, Lyons D, et al. Identification of changes in neuronal function as a consequence of aging and tauopathic neurodegeneration using a novel and sensitive magnetic resonance imaging approach. Neurobiol Aging. (2017) 56:7886. doi: 10.1016/j.neurobiolaging.2017.04.007

98. Tang X, Wu D, Gu LH, Nie BB, Qi XY, Wang YJ, et al. Spatial learning and memory impairments are associated with increased neuronal activity in 5XFAD mouse as measured by manganese-enhanced magnetic resonance imaging. Oncotarget. (2016) 7:57556-70. doi: 10.18632/oncotarget.11353

99. Kam K, Duffy AM, Moretto J, Lafrancois JJ, Scharfman HE. Interictal spikes during sleep are an early defect in the Tg2576 mouse model of beta-amyloid neuropathology. Sci Rep. (2016) 6:20119. doi: 10.1038/srep20119

100. Kawai Y, Aoki I, Umeda M, Higuchi T, Kershaw J, Higuchi M, et al. In vivo visualization of reactive gliosis using manganeseenhanced magnetic resonance imaging. Neuroimage. (2010) 49:3122-31. doi: 10.1016/j.neuroimage.2009.11.005

101. Berkowitz BA, Lenning J, Khetarpal N, Tran C, Wu JY, Berri AM, et al. In vivo imaging of prodromal hippocampus CA1 subfield oxidative stress in models of Alzheimer disease and Angelman syndrome. FASEB J. (2017) 31:4179-86. doi: 10.1096/fj.201700229R

102. Androuin A, Abada YS, Ly M, Santin M, Petiet A, Epelbaum S, et al. Activity-induced MEMRI cannot detect functional brain anomalies in the APPxPS1-Ki mouse model of Alzheimer's disease. Sci Rep. (2019) 9:1140. doi: 10.1038/s41598-018-37980-y

103. Smith KD, Kallhoff V, Zheng H, Pautler RG. In vivo axonal transport rates decrease in a mouse model of Alzheimer's disease. Neuroimage. (2007) 35:1401-8. doi: 10.1016/j.neuroimage.2007.01.046

104. Wesson DW, Levy E, Nixon RA, Wilson DA. Olfactory dysfunction correlates with amyloid-beta burden in an Alzheimer's disease mouse model. J Neurosci. (2010) 30:505-14. doi: 10.1523/JNEUROSCI.4622-09.2010

105. Harrington CR. The molecular pathology of Alzheimer's disease. Neuroimaging Clin N Am. (2012) 22:11-22, vii. doi: 10.1016/j.nic.2011.11.003

106. Saar G, Cheng N, Belluscio L, Koretsky AP. Laminar specific detection of APP induced neurodegeneration and recovery using MEMRI in an olfactory based Alzheimer's disease mouse model. Neuroimage. (2015) 118:18392. doi: 10.1016/j.neuroimage.2015.05.045 
107. Wang FH, Appelkvist P, Klason T, Gissberg O, Bogstedt A, Eliason K, et al. Decreased axonal transport rates in the Tg2576 APP transgenic mouse: improvement with the gamma-secretase inhibitor MRK-560 as detected by manganese-enhanced MRI. Eur J Neurosci. (2012) 36:316572. doi: 10.1111/j.1460-9568.2012.08258.x

108. Majid T, Ali YO, Venkitaramani DV, Jang MK, Lu HC, Pautler RG. In vivo axonal transport deficits in a mouse model of fronto-temporal dementia. Neuroimage Clin. (2014) 4:711-7. doi: 10.1016/j.nicl.2014.02.005

109. Smith KD, Peethumnongsin E, Lin H, Zheng H, Pautler RG. Increased human wildtype tau attenuates axonal transport deficits caused by loss of APP in mouse models. Magn Reson Insights. (2010) 4:118. doi: 10.4137/MRI.S5237

110. Bertrand A, Khan U, Hoang DM, Novikov DS, Krishnamurthy P, Rajamohamed Sait HB, et al. Non-invasive, in vivo monitoring of neuronal transport impairment in a mouse model of tauopathy using MEMRI. Neuroimage. (2013) 64:693-702. doi: 10.1016/j.neuroimage.2012.08.065

111. Smith KD, Paylor R, Pautler RG. R-flurbiprofen improves axonal transport in the Tg2576 mouse model of Alzheimer's disease as determined by MEMRI. Magn Reson Med. (2011) 65:1423-9. doi: 10.1002/mrm.22733

112. Bearer EL, Manifold-Wheeler BC, Medina CS, Gonzales AG, Chaves FL, Jacobs RE. Alterations of functional circuitry in aging brain and the impact of mutated APP expression. Neurobiol Aging. (2018) 70:27690. doi: 10.1016/j.neurobiolaging.2018.06.018

113. Kalia LV, Lang AE. Parkinson's disease. Lancet. (2015) 386:896912. doi: 10.1016/S0140-6736(14)61393-3

114. Saar G, Koretsky AP. Manganese enhanced MRI for use in studying neurodegenerative diseases. Front Neural Circuits. (2019) 12:114. doi: $10.3389 /$ fncir.2018.00114

115. Weng JC, Tikhonova MA, Chen JH, Shen MS, Meng WY, Chang YT, et al. Ceftriaxone prevents the neurodegeneration and decreased neurogenesis seen in a Parkinson's disease rat model: an immunohistochemical and MRI study. Behav Brain Res. (2016) 305:126-39. doi: 10.1016/j.bbr.2016.02.034

116. Olson KE, Bade AN, Schutt CR, Dong J, Shandler SJ, Boska $\mathrm{MD}$, et al. Manganese-enhanced magnetic resonance imaging for detection of vasoactive intestinal peptide receptor 2 agonist therapy in a model of Parkinson's disease. Neurotherapeutics. (2016) 13:635-46. doi: 10.1007/s13311-016-0449-z

117. Kikuta S, Nakamura Y, Yamamura Y, Tamura A, Homma N, Yanagawa $\mathrm{Y}$, et al. Quantitative activation-induced manganese-enhanced MRI reveals severity of Parkinson's disease in mice. Sci Rep. (2015) 5:12800. doi: 10.1038/srep12800

118. Soria G, Aguilar E, Tudela R, Mullol J, Planas AM, Marin C. In vivo magnetic resonance imaging characterization of bilateral structural changes in experimental Parkinson's disease: a T2 relaxometry study combined with longitudinal diffusion tensor imaging and manganese-enhanced magnetic resonance imaging in the 6-hydroxydopamine rat model. Eur J Neurosci. (2011) 33:1551-60. doi: 10.1111/j.1460-9568.2011.07639.x

119. Pelled G, Bergman H, Ben-Hur T, Goelman G. Manganese-enhanced MRI in a rat model of Parkinson's disease. J Magn Reson Imaging. (2007) 26:86370. doi: $10.1002 /$ jmri.21051

120. Oskarsson B, Gendron TF, Staff NP. Amyotrophic lateral sclerosis: an update for 2018. Mayo Clin Proc. (2018) 93:161728. doi: 10.1016/j.mayocp.2018.04.007

121. Chia R, Chio A, Traynor BJ. Novel genes associated with amyotrophic lateral sclerosis: diagnostic and clinical implications. Lancet Neurol. (2018) 17:94-102. doi: 10.1016/S1474-4422(17)30401-5

122. Jouroukhin Y, Ostritsky R, Assaf Y, Pelled G, Giladi E, Gozes I. NAP (davunetide) modifies disease progression in a mouse model of severe neurodegeneration: Protection against impairments in axonal transport. Neurobiol Dis. (2013) 56:79-94. doi: 10.1016/j.nbd.2013.04.012

123. Boretius S, Gadjanski I, Demmer I, Bahr M, Diem R, Michaelis T, et al. MRI of optic neuritis in a rat model. Neuroimage. (2008) 41:32334. doi: 10.1016/j.neuroimage.2008.02.021

124. Wekerle H, Kojima K, Lannes-Vieira J, Lassmann H, Linington C. Animal models. Ann Neurol. (1994) 36(Suppl):S47-53. doi: 10.1002/ana.410360714

125. Gadjanski I, Boretius S, Williams SK, Lingor P, Knoferle J, Sattler MB, et al. Role of n-type voltage-dependent calcium channels in autoimmune optic neuritis. Ann Neurol. (2009) 66:81-93. doi: 10.1002/ana.21668
126. Hoffmann DB, Williams SK, Bojcevski J, Muller A, Stadelmann C, Naidoo $\mathrm{V}$, et al. Calcium influx and calpain activation mediate preclinical retinal neurodegeneration in autoimmune optic neuritis. J Neuropathol Exp Neurol. (2013) 72:745-57. doi: 10.1097/NEN.0b013e31829c7370

127. Fiedorowicz M, Dyda W, Rejdak R, Grieb P. Magnetic resonance in studies of glaucoma. Med Sci Monit. (2011) 17:RA227-32. doi: 10.12659/MSM.881973

128. Chan KC, Fu QL, Hui ES, So KF, Wu EX. Evaluation of the retina and optic nerve in a rat model of chronic glaucoma using in vivo manganese-enhanced magnetic resonance imaging. Neuroimage. (2008) 40:1166-74. doi: 10.1016/j.neuroimage.2008.01.002

129. Dandona L, Hendrickson A, Quigley HA. Selective effects of experimental glaucoma on axonal transport by retinal ganglion cells to the dorsal lateral geniculate nucleus. Invest Ophthalmol Vis Sci. (1991) 32:1593-9.

130. Calkins DJ, Horner PJ, Roberts R, Gradianu M, Berkowitz BA. Manganeseenhanced MRI of the DBA/2J mouse model of hereditary glaucoma. Invest Ophthalmol Vis Sci. (2008) 49:5083-8. doi: 10.1167/iovs.08-2205

131. Yang XL, Van Der Merwe Y, Sims J, Parra C, Ho LC, Schuman JS, et al. Age-related changes in eye, brain and visuomotor behavior in the DBA/2J mouse model of chronic glaucoma. Sci Rep. (2018) 8:4643. doi: 10.1038/s41598-018-22850-4

132. Fiedorowicz M, Orzel J, Kossowski B, Welniak-Kaminska M, Choragiewicz T, Swiatkiewicz M, et al. Anterograde transport in axons of the retinal ganglion cells and its relationship to the intraocular pressure during aging in mice with hereditary pigmentary glaucoma. Curr Eye Res. (2018) 43:53946. doi: 10.1080/02713683.2017.1416147

133. Berkowitz BA, Roberts R, Goebel DJ, Luan H. Noninvasive and simultaneous imaging of layer-specific retinal functional adaptation by manganese-enhanced MRI. Invest Ophthalmol Vis Sci. (2006) 47:266874. doi: $10.1167 /$ iovs. $05-1588$

134. Schur RM, Sheng L, Sahu B, Yu G, Gao S, Yu X, et al. Manganese-enhanced MRI for preclinical evaluation of retinal degeneration treatments. Invest Ophthalmol Vis Sci. (2015) 56:4936-42. doi: 10.1167/iovs.15-16522

135. Berkowitz BA, Grady EM, Khetarpal N, Patel A, Roberts R. Oxidative stress and light-evoked responses of the posterior segment in a mouse model of diabetic retinopathy. Invest Ophthalmol Vis Sci. (2015) 56:60615. doi: 10.1167/iovs.14-15687

136. Berkowitz BA, Gradianu M, Schafer S, Jin Y, Porchia A, Iezzi R, et al. Ionic dysregulatory phenotyping of pathologic retinal thinning with manganese-enhanced MRI. Invest Ophthalmol Vis Sci. (2008) 49:317884. doi: $10.1167 /$ iovs. $08-1720$

137. Ho LC, Wang B, Conner IP, Van Der Merwe Y, Bilonick RA, Kim SG, et al. In vivo evaluation of white matter integrity and anterograde transport in visual system after excitotoxic retinal injury with multimodal MRI and OCT. Invest Ophthalmol Vis Sci. (2015) 56:3788-800. doi: 10.1167/iovs.14-15552

138. Berkowitz BA, Gradianu M, Bissig D, Kern TS, Roberts R. Retinal ion regulation in a mouse model of diabetic retinopathy: natural history and the effect of $\mathrm{Cu} / \mathrm{Zn}$ superoxide dismutase overexpression. Invest Ophthalmol Vis Sci. (2009) 50:2351-8. doi: 10.1167/iovs.08-2918

139. Berkowitz BA, Roberts R, Stemmler A, Luan H, Gradianu M. Impaired apparent ion demand in experimental diabetic retinopathy: correction by lipoic acid. Invest Ophthalmol Vis Sci. (2007) 48:4753-8. doi: 10.1167/iovs.07-0433

140. Muir ER, Chandra SB, De La Garza BH, Velagapudi C, Abboud HE., Duong TQ. Layer-specific manganese-enhanced MRI of the diabetic rat retina in light and dark adaptation at 11.7 Tesla. Invest Ophthalmol Vis Sci. (2015) 56:4006-12. doi: 10.1167/iovs.14-16128

141. Kancherla S, Kohler WJ, Van Der Merwe Y, Chan KC. In Vivo Evaluation of the Visual Pathway in Streptozotocin-Induced Diabetes by Diffusion Tensor MRI and Contrast Enhanced MRI. PLoS ONE. (2016) 11:e0165169. doi: 10.1371/journal.pone. 0165169

142. Astrup J, Siesjo BK, Symon L. Thresholds in cerebral ischemia - the ischemic penumbra. Stroke. (1981) 12:723-5. doi: 10.1161/01.STR.12.6.723

143. Aoki I, Ebisu T, Tanaka C, Katsuta K, Fujikawa A, Umeda M, et al. Detection of the anoxic depolarization of focal ischemia using manganese-enhanced MRI. Magn Reson Med. (2003) 50:7-12. doi: 10.1002/mrm.10528

144. Hoogenboom WS, Rubin TG, Ye K, Cui MH, Branch KC, Liu J, et al. Diffusion tensor imaging of the evolving response 
to mild traumatic brain injury in rats. $J$ Exp Neurosci. 13:1179069519858627. doi: 10.1177/1179069519858627

145. Kazam JJ, Tsiouris AJ. Brain magnetic resonance imaging for traumatic brain injury: why, when, and how? Top Magn Reson Imaging. (2015) 24:225-39. doi: 10.1097/RMR.0000000000000061

146. Meyer EJ, Stout JN, Chung AW, Grant PE, Mannix R, Gagoski B. Longitudinal changes in magnetic resonance spectroscopy in pediatric concussion: a pilot study. Front Neurol. (2019) 10:556. doi: 10.3389/fneur.2019.00556

147. Bouilleret V, Cardamone L, Liu YR, Fang K, Myers DE, O’brien TJ. Progressive brain changes on serial manganese-enhanced MRI following traumatic brain injury in the rat. J Neurotrauma. (2009) 26:19992013. doi: 10.1089/neu.2009.0943

148. Talley Watts L, Shen Q, Deng S, Chemello J, Duong TQ. Manganese-enhanced magnetic resonance imaging of traumatic brain injury. J Neurotrauma. (2015) 32:1001-10. doi: 10.1089/neu.20 14.3737

149. Rodriguez O, Schaefer ML, Wester B, Lee YC, Boggs N, Conner HA, et al. Manganese-enhanced magnetic resonance imaging as a diagnostic and dispositional tool after mild-moderate blast traumatic brain injury. $J$ Neurotrauma. (2016) 33:662-71. doi: 10.1089/neu.2015.4002

150. Ouyang J, Pace E, Lepczyk L, Kaufman M, Zhang J, Perrine SA, et al. Blast-induced tinnitus and elevated central auditory and limbic activity in rats: a manganese-enhanced MRI and behavioral study. Sci Rep. (2017) 7:4852. doi: 10.1038/s41598-017-04941-w

151. Tang HL, Sun HP, Wu X, Sha HY, Feng XY, Zhu JH. Detection of neural stem cells function in rats with traumatic brain injury by manganese-enhanced magnetic resonance imaging. Chin Med J. (2011) 124:1848-53. doi: 10.3760/cma.j.issn.0366-6999.2011.12.016

152. Jiang L, Li R, Tang H, Zhong J, Sun H, Tang W, et al. MRI tracking of iPS cells-induced neural stem cells in traumatic brain injury rats. Cell Transplant. (2018) 28:747-55. doi: 10.1177/0963689718819994

153. Yang J, Wu EX. Detection of cortical gray matter lesion in the late phase of mild hypoxic-ischemic injury by manganese-enhanced MRI. Neuroimage. (2008) 39:669-79. doi: 10.1016/j.neuroimage.2007. 09.009

154. Yang J, Khong PL, Wang Y, Chu AC, Ho SL, Cheung PT, et al. Manganese-enhanced MRI detection of neurodegeneration in neonatal hypoxic-ischemic cerebral injury. Magn Reson Med. (2008) 59:132939. doi: $10.1002 / \mathrm{mrm} .21484$

155. Wideroe M, Olsen O, Pedersen TB, Goa PE, Kavelaars A, Heijnen $\mathrm{C}$, et al. Manganese-enhanced magnetic resonance imaging of hypoxicischemic brain injury in the neonatal rat. Neuroimage. (2009) 45:88090. doi: 10.1016/j.neuroimage.2008.12.007

156. Wideroe M, Brekken C, Kavelaars A, Pedersen TB, Goa PE, Heijnen C, et al. Longitudinal manganese-enhanced magnetic resonance imaging of delayed brain damage after hypoxic-ischemic injury in the neonatal rat. Neonatology. (2011) 100:363-72. doi: 10.1159/000328705

157. Wideroe M, Havnes MB, Morken TS, Skranes J, Goa PE, Brubakk AM. Doxycycline treatment in a neonatal rat model of hypoxiaischemia reduces cerebral tissue and white matter injury: a longitudinal magnetic resonance imaging study. Eur J Neurosci. (2012) 36:200616. doi: 10.1111/j.1460-9568.2012.08114.x

158. Morken TS, Wideroe M, Vogt C, Lydersen S, Havnes M, Skranes J, et al. Longitudinal diffusion tensor and manganese-enhanced MRI detect delayed cerebral gray and white matter injury after hypoxia-ischemia and hyperoxia. Pediatr Res. (2013) 73:171-9. doi: 10.1038/pr.2012.170

159. Moore HC. An overview of chemotherapy-related cognitive dysfunction, or 'chemobrain'. Oncology. (2014) 28:797-804.

160. Matsos A, Johnston IN. Chemotherapy-induced cognitive impairments: a systematic review of the animal literature. Neurosci Biobehav Rev. (2019) 102:382-99. doi: 10.1016/j.neubiorev.2019.05.001

161. Shi DD, Huang YH, Lai CSW, Dong CM, Ho LC, Wu EX, et al. Chemotherapy-induced cognitive impairment is associated with cytokine dysregulation and disruptions in neuroplasticity. Mol Neurobiol. (2019) 56:2234-43. doi: 10.1007/s12035-018-1224-4

162. Shi DD, Dong CM, Ho LC, Lam CTW, Zhou XD, Wu EX, et al. Resveratrol, a natural polyphenol, prevents chemotherapy-induced cognitive impairment:
Involvement of cytokine modulation and neuroprotection. Neurobiol Dis. (2018) 114:164-73. doi: 10.1016/j.nbd.2018.03.006

163. Naughton SX, Hernandez CM, Beck WD, Poddar I, Yanasak N, Lin PC, et al. Repeated exposures to diisopropylfluorophosphate result in structural disruptions of myelinated axons and persistent impairments of axonal transport in the brains of rats. Toxicology. (2018) 406-407:92103. doi: 10.1016/j.tox.2018.06.004

164. Saito S, Aoki I, Sawada K, Suhara T. Quantitative assessment of central nervous system disorder induced by prenatal X-ray exposure using diffusion and manganese-enhanced MRI. NMR Biomed. (2012) 25:7583. doi: $10.1002 / \mathrm{nbm} .1715$

165. Saito S, Sawada K, Aoki I. Prenatal irradiation-induced hippocampal abnormalities in rats evaluated using manganese-enhanced MRI. Front Neural Circuits. (2018) 12:112. doi: 10.3389/fncir.2018. 00112

166. Saito S, Hasegawa S, Sekita A, Bakalova R, Furukawa T, Murase K, et al. Manganese-enhanced MRI reveals early-phase radiation-induced cell alterations in vivo. Cancer Res. (2013) 73:3216-24. doi: 10.1158/0008-5472.CAN-12-3837

167. Hsu YH, Lee WT, Chang C. Multiparametric MRI evaluation of kainic acidinduced neuronal activation in rat hippocampus. Brain. (2007) 130:312434. doi: 10.1093/brain/awm207

168. Malheiros JM, Longo BM, Tannus A, Covolan L. Manganeseenhanced magnetic resonance imaging in the acute phase of the pilocarpine-induced model of epilepsy. Einstein. (2012) 10:247-52. doi: 10.1590/S1679-45082012000200023

169. Malheiros JM, Persike DS, Castro LU, Sanches TR, Andrade Lda C, Tannus A, et al. Reduced hippocampal manganese-enhanced MRI (MEMRI) signal during pilocarpine-induced status epilepticus: edema or apoptosis? Epilepsy Res. (2014) 108:644-52. doi: 10.1016/j.eplepsyres.2014.02.007

170. Immonen RJ, Kharatishvili I, Sierra A, Einula C, Pitkanen A, Grohn OH. Manganese enhanced MRI detects mossy fiber sprouting rather than neurodegeneration, gliosis or seizureactivity in the epileptic rat hippocampus. Neuroimage. (2008) 40:1718-30. doi: 10.1016/j.neuroimage.2008.01.042

171. Alvestad S, Goa PE, Qu H, Risa O, Brekken C, Sonnewald U, et al. In vivo mapping of temporospatial changes in manganese enhancement in rat brain during epileptogenesis. Neuroimage. (2007) 38:57-66. doi: 10.1016/j.neuroimage.2007.07.027

172. Fukumura S, Sasaki M, Kataoka-Sasaki Y, Oka S, Nakazaki M, Nagahama H, et al. Intravenous infusion of mesenchymal stem cells reduces epileptogenesis in a rat model of status epilepticus. Epilepsy Res. (2018) 141:5663. doi: 10.1016/j.eplepsyres.2018.02.008

173. Quarantelli M. MRI/MRS in neuroinflammation: methodology and applications. Clin Transl Imaging. (2015) 3:47589. doi: 10.1007/s40336-015-0142-y

174. Bade AN, Gorantla S, Dash PK, Makarov E, Sajja BR, Poluektova LY, et al. Manganese-enhanced magnetic resonance imaging reflects brain pathology during progressive HIV-1 infection of humanized mice. Mol Neurobiol. (2016) 53:3286-97. doi: 10.1007/s12035-0159258-3

175. Thinschmidt JS, Colon-Perez LM, Febo M, Caballero S, King MA, White FA, et al. Depressed basal hypothalamic neuronal activity in type-1 diabetic mice is correlated with proinflammatory secretion of HMBG1. Neurosci Lett. (2016) 615:21-7. doi: 10.1016/j.neulet.2016. 01.014

176. Dudek M, Abo-Ramadan U, Hermann D, Brown M, Canals S, Sommer WH, et al. Brain activation induced by voluntary alcohol and saccharin drinking in rats assessed with manganese-enhanced magnetic resonance imaging. Addict Biol. (2015) 20:1012-21. doi: 10.1111/adb.12179

177. Dudek M, Hyytia P. Alcohol preference and consumption are controlled by the caudal linear nucleus in alcohol-preferring rats. Eur J Neurosci. (2016) 43:1440-8. doi: 10.1111/ejn. 13245

178. Dudek M, Canals S, Sommer WH, Hyytia P. Modulation of nucleus accumbens connectivity by alcohol drinking and naltrexone in alcohol-preferring rats: a manganese-enhanced magnetic resonance imaging study. Eur Neuropsychopharmacol. (2016) 26:445-55. doi: 10.1016/j.euroneuro.2016.01.003 
179. Bade AN, Gendelman HE, Boska MD, Liu Y. MEMRI is a biomarker defining nicotine-specific neuronal responses in subregions of the rodent brain. Am J Transl Res. (2017) 9:601-10.

180. Topping GJ, Schaffer P, Hoehr C, Ruth TJ, Sossi V. Manganese-52 positron emission tomography tracer characterization and initial results in phantoms and in vivo. Med Phys. (2013) 40:042502. doi: 10.1118/1.4793756

181. Saar G, Millo CM, Szajek LP, Bacon J, Herscovitch P, Koretsky AP. Anatomy, functionality, and neuronal connectivity with manganese radiotracers for positron emission tomography. Mol Imaging Biol. (2018) 20:56274. doi: 10.1007/s11307-018-1162-6
Conflict of Interest: The authors declare that the research was conducted in the absence of any commercial or financial relationships that could be construed as a potential conflict of interest.

Copyright (c) 2020 Yang and Li. This is an open-access article distributed under the terms of the Creative Commons Attribution License (CC BY). The use, distribution or reproduction in other forums is permitted, provided the original author(s) and the copyright owner(s) are credited and that the original publication in this journal is cited, in accordance with accepted academic practice. No use, distribution or reproduction is permitted which does not comply with these terms. 